\title{
Targeting the PTTG1 oncogene impairs proliferation and invasiveness of melanoma cells sensitive or with acquired resistance to the BRAF inhibitor dabrafenib
}

\author{
Simona Caporali ${ }^{1}$, Ester Alvino ${ }^{2}$, Pedro Miguel Lacal ${ }^{1}$, Federica Ruffini ${ }^{1}$, Lauretta \\ Levati $^{1}$, Laura Bonmassar ${ }^{1}$, Alessandro Scoppola ${ }^{3}$, Paolo Marchetti ${ }^{3,4}$, Simona \\ Mastroeni ${ }^{5}$, Gian Carlo Antonini Cappellini ${ }^{3}$ and Stefania D'Atri ${ }^{1}$ \\ 1'Laboratory of Molecular Oncology, Istituto Dermopatico dell'Immacolata-IRCCS, Rome, Italy \\ ${ }^{2}$ Institute of Translational Pharmacology, National Council of Research, Rome, Italy \\ ${ }^{3}$ Department of Oncology and Dermatological Oncology, Istituto Dermopatico dell'Immacolata-IRCCS, Rome, Italy \\ ${ }^{4}$ UOC Oncologia, University of Rome "La Sapienza", Rome, Italy \\ ${ }^{5}$ Clinical Epidemiology Unit, Istituto Dermopatico dell'Immacolata-IRCCS, Rome, Italy \\ Correspondence to: Stefania D'Atri, email: s.datri@idi.it \\ Keywords: melanoma; proliferation; invasion; PTTG 1; dabrafenib \\ Received: August 03, $2017 \quad$ Accepted: November 13,2017 Published: December 09, 2017 \\ Copyright: Caporali et al. This is an open-access article distributed under the terms of the Creative Commons Attribution License 3.0 \\ (CC BY 3.0), which permits unrestricted use, distribution, and reproduction in any medium, provided the original author and source \\ are credited.
}

\section{ABSTRACT}

The pituitary tumor transforming gene 1 (PTTG1) is implicated in tumor growth, metastasis and drug resistance. Here, we investigated the involvement of PTTG1 in melanoma cell proliferation, invasiveness and response to the BRAF inhibitor (BRAFi) dabrafenib. We also preliminary assessed the potential value of circulating PTTG1 protein to monitor melanoma patient response to BRAFi or to dabrafenib plus trametinib. Dabrafenib-resistant cell lines (A375R and SK-Mel28R) were more invasive than their drug-sensitive counterparts (A375 and SK-Mel28), but expressed comparable PTTG1 levels. Dabrafenib abrogated PTTG1 expression and impaired invasion of the extracellular matrix (ECM) in A375 and SK-Mel28 cells. In contrast, it affected neither PTTG1 expression in A375R and SK-Mel28R cells, nor ECM invasion in the latter cells, while further stimulated A375R cell invasiveness. Assessment of proliferation and ECM invasion in control and PTTG1-silenced A375 and SK-Mel28 cells, exposed or not to dabrafenib, demonstrated that the inhibitory effects of this drug were, at least in part, dependent on its ability to down-regulate PTTG1 expression. PTTG1-silencing also impaired proliferation and invasiveness of A375R and SK-Mel28R cells, and counteracted dabrafenib-induced stimulation of ECM invasion in A375R cells. Further experiments performed in A375R cells indicated that PTTG1-silencing impaired cell invasiveness through inhibition of MMP-9 and that PTTG1 expression and ECM invasion could be also reduced by the CDK4/6 inhibitor LEE011. PTTG1 targeting might, therefore, represent a useful strategy to impair proliferation and metastasis of melanomas resistant to BRAFi. Circulating PTTG1 also appeared to deserve further investigation as biomarker to monitor patient response to targeted therapy. 


\section{INTRODUCTION}

The pituitary tumor transforming gene 1 (PTTG1), codes for a multifunctional protein involved in a variety of cellular processes [reviewed in 1-4]. As a vertebrate securin, the PTTG1 protein plays a crucial role in the regulation of sister chromatid separation during mitosis [1-4]. In addition, it participates in DNA repair, apoptosis, senescence, metabolism and gene transcription [1-4].

PTTG1 is considered an oncogene $[5,6]$, and it is over-expressed in a variety of cancer cell lines as well as in a wide range of primary and metastatic tumors $[1-4$, 7-12], including melanoma [13]. Notably, PTTG1 is one of the 17 gene-expression signature predicting metastasis and shorter survival in multiple tumor types [14] and it is among the top- 20 genes whose elevated expression was found to be associated with metastatic dissemination of melanoma $[15,16]$. The involvement of PTTG1 in tumor growth and metastasis is further highlighted by several studies showing that in cancer cell lines of various histological derivation ectopic expression of PTTG1 enhanced proliferation and/or invasiveness, whereas PTTG1 silencing produced opposite results $[7,8,10-12$, 17-22].

Multiple molecular mechanisms appear to underlie the growth and invasion promoting activity of PTTG1. For instance, Yoon et al. [7] demonstrated that in breast cancer cells PTTG1 promotes epithelial to mesenchymal transition (EMT) and expansion of the cancer stem cell population via AKT activation, while Zhang et al. [17] reported that PTTG1 enhanced breast cancer cell proliferation through inhibition of TGF- $\beta$ signaling. PTTG1 can also affect the invasive capacity of cancer cells through positive modulation of several matrix metalloproteinases (MMPs) [8, 10, 18, 21].

A number of experimental evidences also support a role of PTTG1 in the regulation of cancer cell response to therapy. PTTG1 interacts with p53 and negatively modulates p53-mediated transcriptional activity and apoptosis [23]. On the other hand, p53 was shown to directly repress $P T T G 1$ transcription, and this molecular event was suggested to contribute to apoptosis induced by p53 up-regulation in colon cancer cells treated with 5-fluorouracil [24]. PTTG1 loss was also demonstrated to increase colon cancer cell sensitivity to ionizing radiation, adriamycin, doxorubicin or Trichostatin A [25, 26]. In breast cancer, $P T T G 1$ was among the eight genes significantly overexpressed in tumor specimens of patients who relapsed on tamoxifen treatment as compared with tumor of patients who did not [27]. Furthermore, high levels of PTTG1 were found to promote resistance to gefitinib-induced apoptosis in various tumor cell lines [28] and to be associated with saracatinib resistance in ovarian cancer cells [29].
Although PTTG1 is over-expressed in melanoma specimens [13] and is included in the gene panel identifying a metastatic behavior in this tumor $[15,16]$, no data are available on the biological activity of the PTTG1 protein in melanoma cells, with exception of a previous study by our group [30]. In that investigation we showed that PTTG1 silencing inhibited proliferation of melanoma cells and that the growth suppressive effects of the cyclin-dependent kinase (CDK) inhibitor PHA-848125 was in part dependent on drug-induced down-regulation of PTTG1.

In the present study, we investigated the role of PTTG1 in melanoma cell proliferation, invasiveness and response to the BRAF inhibitor (BRAFi) dabrafenib by using two pairs of syngeneic melanoma cell lines sensitive or with acquired resistance to the drug. Moreover, based on our results, we assessed whether changes of PTTG1 plasma levels occur in melanoma patients subjected to therapy with BRAFi or the combination of dabrafenib plus the MEK inhibitor (MEKi) trametinib.

\section{RESULTS}

\section{Generation and characterization of the SK- Mel28R subline with acquired resistance to dabrafenib}

We previously reported that the dabrafenib-resistant A375R cell line was more invasive and secreted higher levels of VEGF-A and MMP-9 as compared with the parental A375 cell line [31]. We also showed that exposure to dabrafenib reduced invasiveness and VEGF-A secretion in A375 cells, whereas it increased invasiveness, VEGF-A and MMP-9 release in A375R cells [31].

In the present study, we generated an additional dabrafenib-resistant cell line, (i.e. SK-Mel28R), that was compared to its parental cell line (i.e. SK-Mel28) for the ability to invade the extracellular matrix (ECM), under basal condition and in response to exogenously added VEGF-A, as well as for VEGF-A and MMP-9 secretion. The effects of dabrafenib treatment on these cellular processes were also investigated in both cell lines.

MTT assays, performed after five days of cell culture with graded concentrations of dabrafenib, confirmed that SK-Mel28 cells were highly susceptible to the growth suppressive effects of dabrafenib, even though the drug $\mathrm{IC}_{50}$ value was about 3-fold higher than that previously observed in A375 cells [31]. In contrast, proliferation of SK-Mel28R cells was not affected by drug concentrations up to $800 \mathrm{nM}$, and even stimulated by drug concentrations ranging between 1600 $\mathrm{nM}$ and $6400 \mathrm{nM}$ (Figure 1A). In agreement with the results obtained with $\mathrm{A} 375$ and $\mathrm{A} 375 \mathrm{R}$ cell lines, which were included in the invasion assays for comparison 
(Figure 1B), SK-Mel-28R cells were about 2-fold more invasive than the corresponding dabrafenib-sensitive parental cells (Figure 1C). However, while exposure to VEGF-A caused an increase of ECM invasion in both A375 and A375R cells, as previously reported [31], only SK-Mel28 cells responded to this cytokine (Figure 1C).

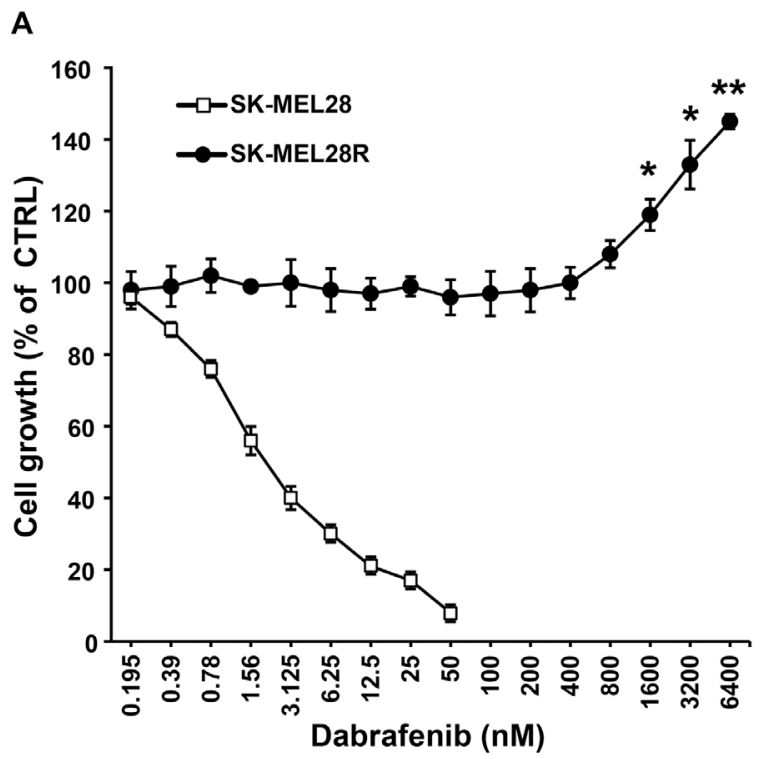

Consistent with the data on A375 cells, dabrafenib significantly inhibited spontaneous and VEGF-A-induced ECM invasion in SK-Mel28 cells. However, differently from what occurring in A375R cells, invasiveness of SKMel28R cells was not further stimulated by exposure to dabrafenib (Figure 1C).

\section{B}
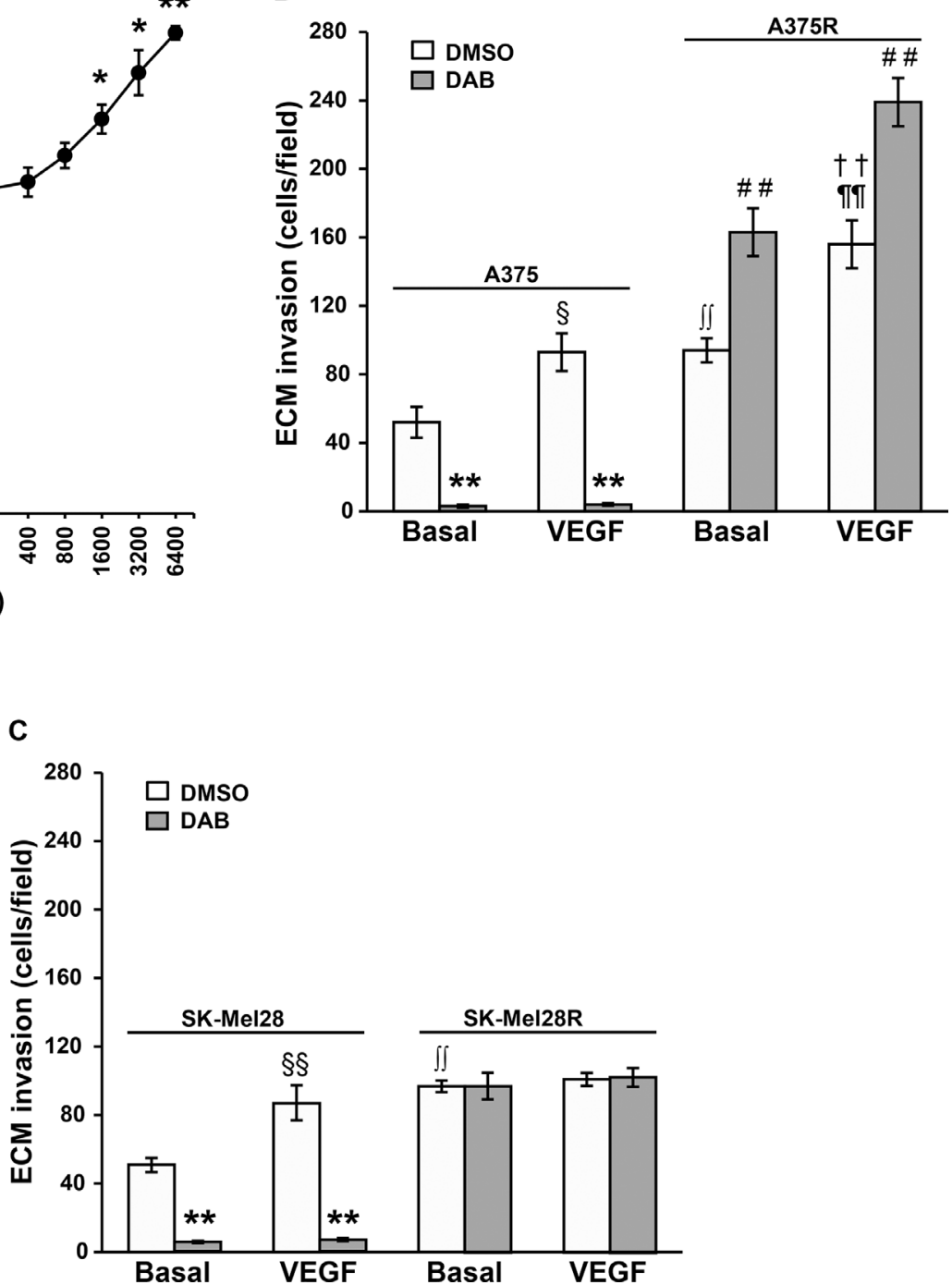

Figure 1: Characterization of the dabrafenib-resistant SK-Mel28R cells. (A) SK-Mel28 and SK-Mel28R cells were incubated with graded concentrations of dabrafenib or with DMSO alone for five days and then proliferation was assessed by the MTT assay. Data are expressed in terms of percentage of growth of cells treated with dabrafenib with respect to cells treated with DMSO alone (CTRL). Each value represents the arithmetic mean of four (SK-Mel28) or three (SK-Mel28R) independent experiments. Bars, standard error of the mean (SEM). For each experiment, the dabrafenib $\mathrm{IC}_{50}$ value was calculated as described in the "Materials and methods" section. The $\mathrm{IC}_{50}$ mean value \pm SEM was $3.05 \pm 0.39 \mathrm{nM}$ for SK-Mel28 cells and not assessable for SK-Mel28R cells. ${ }^{* *} P<0.01$ and ${ }^{*} P<0.05$ comparing dabrafenib-treated with DMSO-treated SK-Mel28R cells. (B) A375 and A375R cells were cultured in the presence of $100 \mathrm{nM}$ dabrafenib (DAB) or DMSO alone for $48 \mathrm{~h}$. Thereafter, cell ability to invade the ECM, either spontaneously (Basal) or in response to VEGF-A was evaluated. Data are expressed as number of invaded cells per microscopic field. Each value represents the arithmetic mean $\pm \mathrm{SEM}$ of four independent experiments. ${ }^{\$} P<0.05$ A375/VEGF-A versus (vs) A375/Basal; ${ }^{* *} P<0.01$ A375/DAB $v s$ A375/DMSO; ${ }^{\dagger} P<0.01 \mathrm{~A} 375 \mathrm{R} /$ VEGF-A vs A375R/Basal; ${ }^{\prime} P<0.01$ A375R/DAB vs A375R/DMSO; $P<0.01$ A375R/basal vs A375/basal; " $P<0.01$ A375R/VEGF-A vs A375/VEGF-A. (C) SK-Mel28 and SK-Mel28R were treated and analyzed for ECM invasion as described in (B). Data are expressed as number of invaded cells per microscopic field. Each value represents the arithmetic mean \pm SEM of six (SK-Mel28) or four (SK-Mel28R) independent experiments. ${ }^{\$} P<0.01$ SK-Mel28/VEGF-A vs SK-Mel28/Basal; ${ }^{* *} P<0.01$ SK-Mel28/DAB $v s$ SK-Mel28/DMSO; ${ }^{\int f} P<0.01$ SK-Mel28R/basal vs SK-Mel28/basal. 
Table 1: VEGF-A and MMP-9 secretion in A375 and SK-Mel28 cell lines and their dabrafenib-resistant counterparts

\begin{tabular}{|c|c|c|c|c|c|c|}
\hline \multirow{2}{*}{ Cell Line } & \multicolumn{3}{|c|}{ VEGF-A $\left(\mathrm{ng} / 10^{6}{\text { cells })^{\mathrm{a}}}^{\mathrm{a}}\right.$} & \multicolumn{3}{|c|}{ MMP-9 $\left(\mathrm{pg} / 10^{6} \text { cells }\right)^{\mathrm{a}}$} \\
\hline & DMSO $^{b}$ & Dabrafenib $^{\mathbf{b}}$ & $P^{c}$ & DMSO $^{\text {b }}$ & Dabrafenib $^{\text {b }}$ & $P^{c}$ \\
\hline SK-Mel28 & $1.48 \pm 0.13$ & $0.50 \pm 0.06$ & $<0.01$ & $5.15 \pm 0.64$ & $0.50 \pm 0.07$ & $<0.01$ \\
\hline SK-Mel28R & $76.00 \pm 7.61^{* *}$ & $82.98 \pm 9.38^{* *}$ & NS & $83.75 \pm 9.91^{* *}$ & $95.75 \pm 16.82^{* *}$ & NS \\
\hline A375 (ref. 31) & $7.48 \pm 1.27$ & $3.50 \pm 0.98$ & $<0.05$ & $24.25 \pm 2.10$ & $24.75 \pm 6.52$ & NS \\
\hline A375R (ref. 31) & $15.83 \pm 1.47^{* *}$ & $26.04 \pm 2.66^{* *}$ & $<0.05$ & $47.88 \pm 3.79^{* *}$ & $75.75 \pm 4.09^{* *}$ & $<0.01$ \\
\hline
\end{tabular}

The amount of VEGF-A and MMP-9 in cell culture supernatants was determined by ELISA.

${ }^{\mathrm{b}}$ cells were cultured with $100 \mathrm{nM}$ dabrafenib or DMSO alone for $48 \mathrm{~h}$ and then culture supernatants were collected and assayed for VEGF-A and MMP-9 content.

' $P$, probability calculated according to Student's $t$-test comparing dabrafenib-treated with DMSO-treated cells.

${ }^{* *} P<0.01$ comparing A375R cells with A375 cells, and SK-Mel28R cells with SK-Mel28 cells.

Table 1 illustrates the amount of VEGF-A and MMP-9 determined in the culture supernatants of SKMel28 and SK-Mel28R cells treated for $48 \mathrm{~h}$ with 100 $\mathrm{nM}$ dabrafenib or the drug vehicle alone (i.e. dimethyl sulfoxide, DMSO). The level of the two polypeptides previously determined in A375 and A375R under the same experimental conditions [31] is also reported for comparison. Basal secretion of VEGF-A and MMP-9 was higher in SK-Mel28R cells as compared with parental SKMel28 cells. Moreover, dabrafenib treatment markedly impaired VEGF-A and MMP-9 secretion in SK-Mel28 cells, whereas it did not affect VEGF-A and MMP-9 secretion in SK-Mel28R cells.

\section{Effects of PTTG1 silencing on melanoma cell proliferation, invasiveness and response to dabrafenib}

To investigate whether PTTG1 plays a role in melanoma cell proliferation, invasiveness and response to dabrafenib, we first examined its expression in A375, A375R, SK-Mel28 and SK-Mel28R cell lines exposed to $100 \mathrm{nM}$ dabrafenib or to DMSO for $48 \mathrm{~h}$.

As illustrated in Figure 2A, basal levels of PTTG1 protein were comparable between the drug-resistant cell lines and their matched parental counterparts. However, while exposure to dabrafenib completely inhibited PTTG1 expression in A375 and SK-Mel28 cells, it did not substantially affect the levels of this protein in A375R and SK-Mel28R cells.

We next evaluated whether down-modulation of PTTG1 was associated with an impairment of cell proliferation. To this end, A375, A375R, SK-Mel28 and SK-Mel28R cells were transfected with either a siRNA targeting PTTG1 (siPTTG1) or a negative control siRNA (siCTRL) and analyzed for proliferation three and six days after transfection using the MTT assay. To confirm that PTTG1 expression was efficiently down-regulated up to the end of the proliferation assay, PTTG1 protein levels in siCTRL- and siPTTG1-transfected cells were determined by Western blot analysis six days after transfection. Evaluation of PTTG1 levels was also performed in the four cell lines that had been transfected with siCTRL or siPTTG1 and $24 \mathrm{~h}$ later incubated with $100 \mathrm{nM}$ dabrafenib or DMSO for additional $48 \mathrm{~h}$.

As illustrated in Supplementary Figure 1A, PTTG1 levels in the four cell lines remained markedly downregulated up to six days after siPTTG1 transfection. Furthermore, expression of PTTG1 was efficiently inhibited in the siPTTG1-transfected cells either exposed to DMSO or to dabrafenib for $48 \mathrm{~h}$ (Figure $2 \mathrm{~B}$ and $2 \mathrm{C}$ ).

Three days after siPTTG1 transfection, proliferation of A375 and A375R cells was significantly inhibited, whereas that of SK-Mel28 and SK-Mel28R cells was only minimally affected (Figure 2D). On the other hand, six days after transfection, down-regulation of PTTG1 was associated with a significant impairment of proliferation in all the cell lines, even though the growth inhibitory effects of PTTG1 silencing were higher in the dabrafenibsensitive cell lines than in their drug-resistant counterparts (Figure 2D).

To assess whether PTTG1 silencing affected melanoma cell sensitivity to the growth suppressive effect of dabrafenib, A375, A375R, SK-Mel28 and SK-Mel28R cells were transfected with either siPTTG1 (hereafter referred to as siPTTG1/cells) or siCTRL (hereafter referred to as siCTRL/cells), and $24 \mathrm{~h}$ later incubated with graded concentrations of the drug. Proliferation was determined after three and five days of culture by the MTT assay. siPTTG1/A375 and siPTTG1/A375R cells did not show any significant increase in dabrafenib sensitivity with respect to their siCTRL-transfected counterparts at both time points analyzed (data not shown). Similarly, no effect of PTTG1 silencing on sensitivity to dabrafenib was observed in SK-Mel 28 and SK-Mel28R cells when proliferation was evaluated after three days of drug exposure (Figure 3A and Figure 3C). On the other hand, siPTTG1/SK-Mel28 cells displayed a reduction of about $40 \%$ of the dabrafenib $\mathrm{IC}_{50}$ value when their proliferation was determined after five days of drug treatment (Figure 3B). Moreover, at this time point, proliferation 


\section{A}

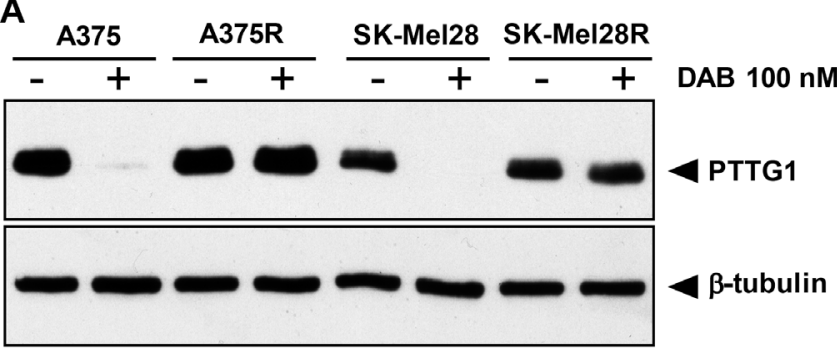

B

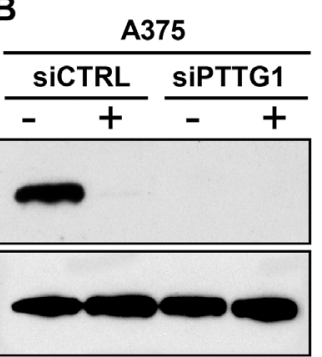

A375R

$\frac{\text { SiCTRL }}{-\quad+\quad \frac{\text { SiPTTG1 }}{-\quad+} \text { DAB } 100 \mathrm{nM}}$

C

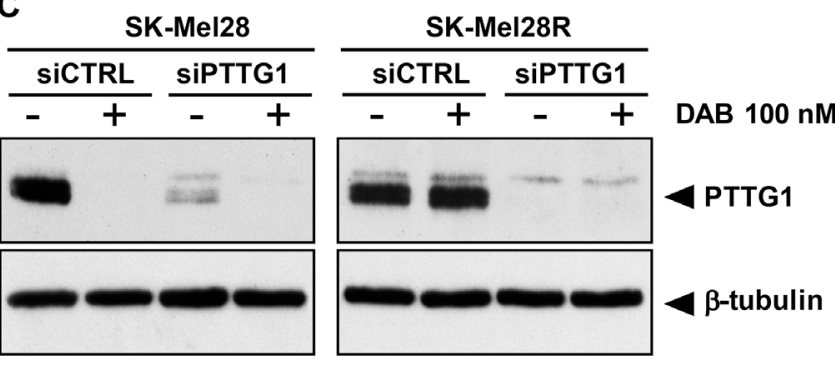

D

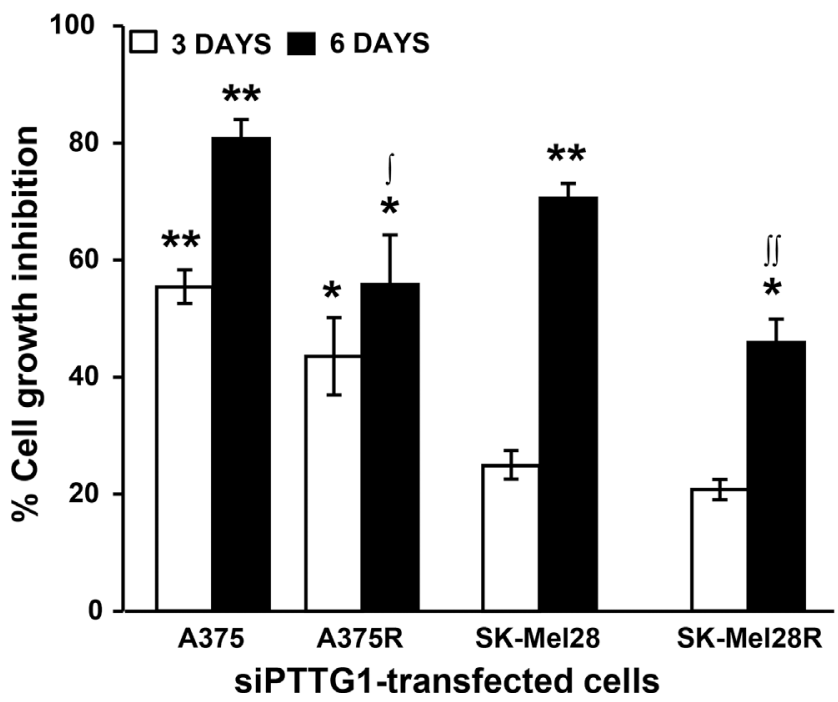

Figure 2: Inhibition of PTTG1 expression impairs proliferation of melanoma cells sensitive or resistant to dabrafenib. (A) Melanoma cells were treated with dabrafenib (DAB) or DMSO alone (-) for $48 \mathrm{~h}$ and then cell lysates were analyzed by immunoblotting using antibodies against PTTG1, or against $\beta$-tubulin as a loading control. The results are representative of three independent experiments. (B) and (C) Melanoma cells were transiently transfected with siPTTG1 or siCTRL and $24 \mathrm{~h}$ later incubated with dabrafenib (DAB) or DMSO alone (-). After $48 \mathrm{~h}$ of culture, cell extracts were prepared and analyzed by immunoblotting using antibodies against PTTG1 or against $\beta$-tubulin. The results are representative of three independent experiments. (D) Melanoma cells were transfected with siPTTG1 or siCTRL and three and six days later assessed for proliferation using the MTT assay. Data are expressed in terms of percentage of cell growth inhibition of siPTTG1-transfected cells with respect to matched siCTRL-transfected cells. Each value represents the arithmetic mean of four independent experiments. Bars, SEM. ${ }^{* *} P<0.01$ and ${ }^{*} P<0.05$ siPTTG1-transfected cells $v s$ matched siCTRL-transfected cells; ${ }^{\|} P<0.01$ and ${ }^{\dagger} P<0.05$ dabrafenib-resistant cells $v s$ matched drug-sensitive cells. 
of siPTTG1/SK-Mel28R cells was lower than that of siCTRL/SK-Mel28R cells at drug concentrations ranging between $1600 \mathrm{nM}$ and $6400 \mathrm{nM}$ (Figure 3D).

To determine whether PTTG1 could be involved in the regulation of the invasive capacity of dabrafenibsensitive or dabrafenib-resistant cells and in the modulation of this cellular process by the drug, A375, A375R, SK-Mel28 and SK-Mel28R cells were transfected with siCTRL or siPTTG1 and analyzed for ECM invasion after a $48 \mathrm{~h}$-exposure to $100 \mathrm{nM}$ dabrafenib or DMSO.

We found that PTTG1 silencing alone caused a significant inhibition of the invasive capacity of the four cell lines (Figure 4A and 4B). Dabrafenib treatment markedly impaired ECM invasion in A375 and SKMel28 cells transfected with either siCTRL or siPTTG1
(Figure 4A and 4B). In both cell lines, inhibition of invasiveness induced by dabrafenib alone was higher than that caused by PTTG1 silencing alone and similar to that induced by dabrafenib plus siPTTG1 (Figure 4A and 4B).

In both siCTRL/A375R and siPTTG1/A375R cells, exposure to dabrafenib promoted ECM invasion. However, invasiveness of drug-treated siPTTG1/ A375R cells was significantly lower than that of drugtreated siCTRL/A375R cells and comparable to that of siCTRL/A375R cells exposed to DMSO (Figure 4A). As expected, exposure to dabrafenib did not modify the invasive capacity of siCTRL/SK-Mel28R cells. The drug was ineffective also in the presence of PTTG1 silencing (Figure 4B).

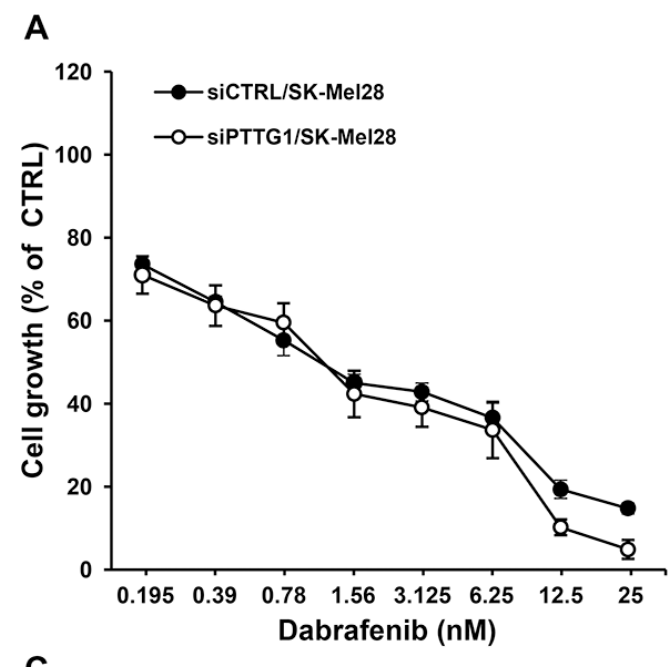

\section{B}
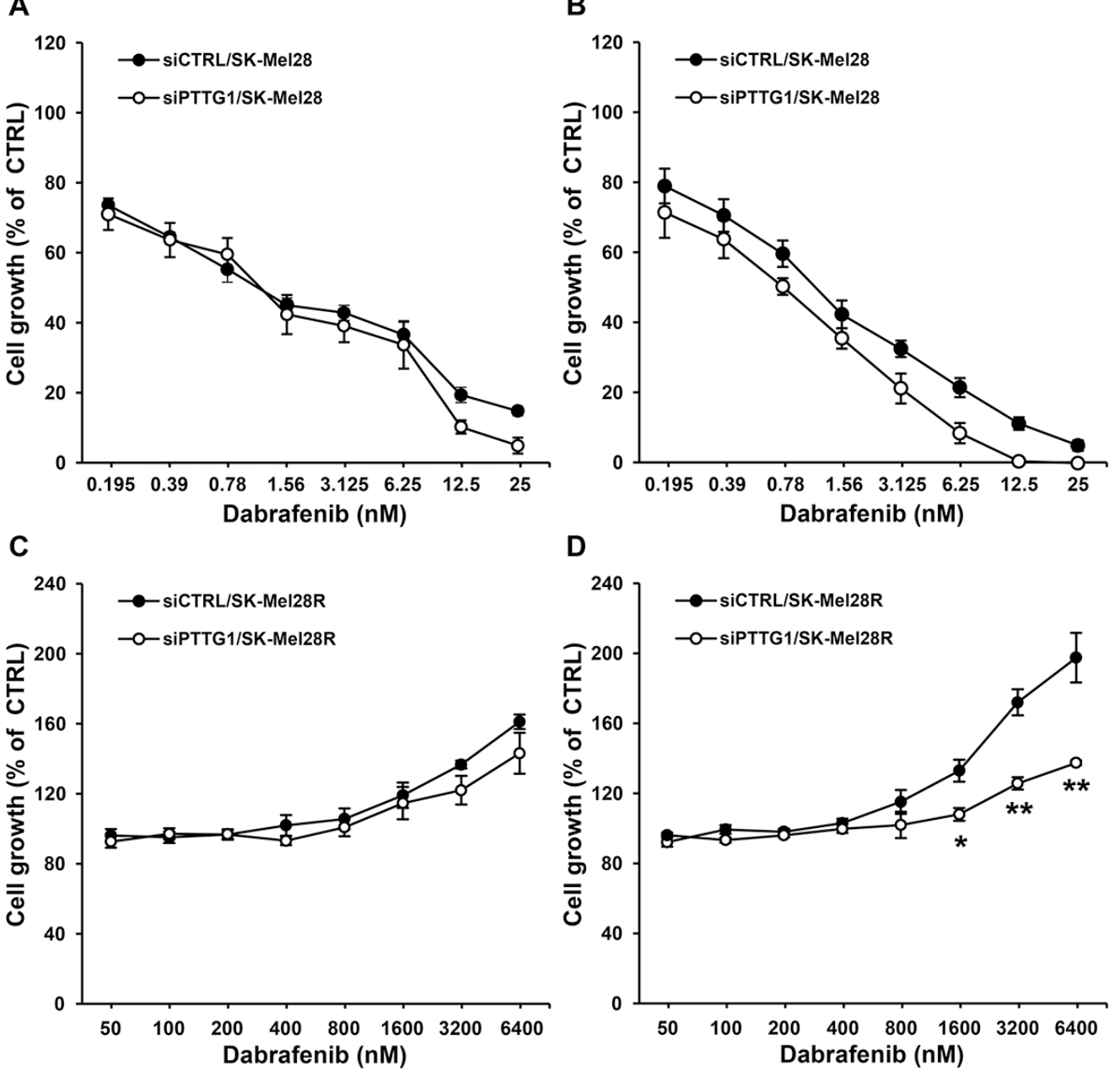

Figure 3: Effect of PTTG1 silencing on SK-Mel28 and SK-Mel28R cell sensitivity to dabrafenib. SK-Mel28 (A, B) and SK-Mel28R (C, D) cells were transiently transfected with siPTTG1 or siCTRL and $24 \mathrm{~h}$ later incubated with dabrafenib or with DMSO alone for three (A, C) or five (B, D) days. Proliferation was then assessed by the MTT assay. Data are expressed in terms of percentage of growth of cells treated with dabrafenib with respect to cells treated with DMSO alone (CTRL). Each value represents the arithmetic mean of four independent experiments. Bars, SEM. For each experiment, the dabrafenib $\mathrm{IC}_{50}$ value was calculated as described in the "Materials and methods" section. The $\mathrm{IC}_{50}$ mean value $\pm \mathrm{SEM}$ after three days of treatment with dabrafenib was $1.38 \pm 0.23 \mathrm{nM}$ for siCTRL/SK-Mel28 cells and $1.08 \pm 0.15 \mathrm{nM}$ for siPTTG1/SK-Mel28 cells. The $\mathrm{IC}_{50}$ mean value $\pm \mathrm{SEM}$ after five days of treatment with dabrafenib was 1.12 $\pm 0.15 \mathrm{nM}$ for siCTRL/SK-Mel28 cells and $0.68 \pm 0.05 \mathrm{nM}$ for siPTTG1/SK-Mel28 cells $(P<0.05)$. IC ${ }_{50}$ values were not assessable for the SK-Mel28R cell line. ${ }^{* *} P<0.01$ and ${ }^{*} P<0.05$ comparing siPTTG1/SK-Mel28R cells with siCTRL/SK-Mel28R cells at the indicated concentrations of dabrafenib. 


\section{Effects of PTTG1 over-expression on melanoma cell proliferation, invasiveness and response to dabrafenib}

To evaluate the effect of PTTG1 over-expression on melanoma cell proliferation, A375 cells were transiently transfected with an expression vector encoding a FLAGtagged PTTG1 protein (CMV-PTTG1) or with the empty vector (CMV-EV). Six days after transfection, cells were analyzed for proliferation using the MTT assay and processed for Western blot analysis to confirm PTTG1FLAG expression. Western blot analysis of PTTG1 levels was also performed in the cells that had been transfected with CMV-PTTG1 or CMV-EV and $24 \mathrm{~h}$ later incubated with $100 \mathrm{nM}$ dabrafenib or DMSO for additional $48 \mathrm{~h}$.

As illustrated in Figure 5A, FLAG-tagged PTTG1 protein was successfully over-expressed in CMV-PTTG1transfected cells, and remained at elevated levels up to six days after transfection (Supplementary Figure 1B). Exposure to dabrafenib for $48 \mathrm{~h}$ abrogated PTTG1 expression in CMV-EV cells and reduced the amount of endogenous and FLAG-tagged PTTG1 protein in CMVPTTG1 cells.

PTTG1 over-expression was not associated with an increase of A375 cell proliferation (data not shown). Moreover, CMV-PTTG1 cells did not show increased resistance to the antiproliferative effects of dabrafenib as determined by MTT assays (data not shown).

A375 cells transfected with either the CMV-PTTG1 or CMV-EV vector were also analyzed for the ability to invade the ECM after a $48 \mathrm{~h}$-exposure to $100 \mathrm{nM}$ dabrafenib or DMSO.

The results illustrated in Figure 5B show that invasiveness of CMV-PTTG1 cells was significantly higher than that of the cells transfected with the empty vector. In both control and PTTG1 over-expressing cells,

A

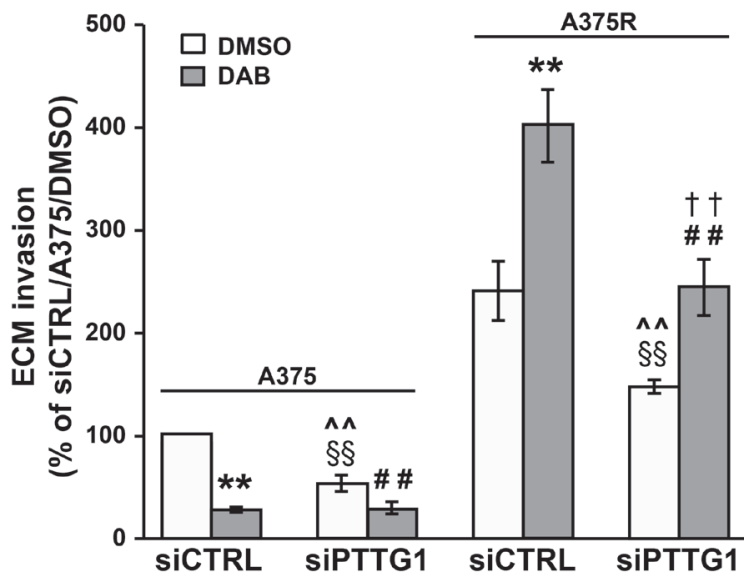

B

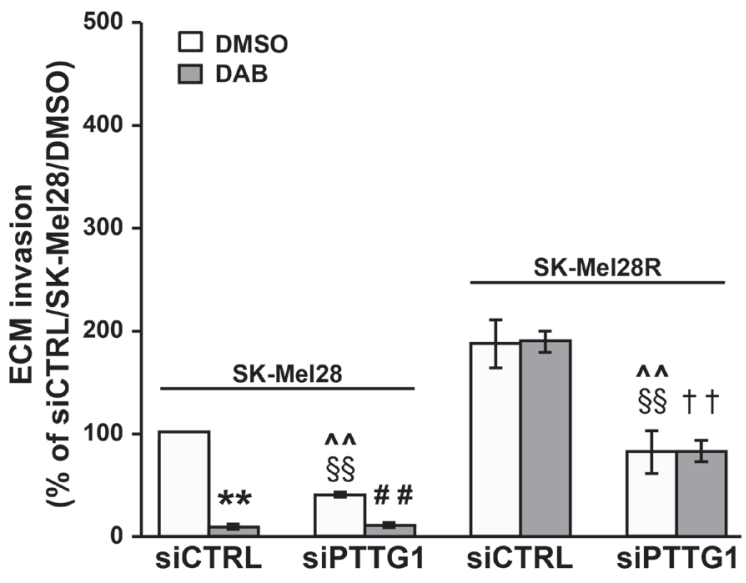

Figure 4: Inhibition of PTTG1 expression impairs invasiveness of melanoma cells sensitive or resistant to dabrafenib. A375 and A375R cells (A) as well as SK-Mel28 and SK-Mel28R cells (B) were transiently transfected with siPTTG1 or siCTRL and $24 \mathrm{~h}$ later incubated with $100 \mathrm{nM}$ dabrafenib (DAB) or DMSO alone. After $48 \mathrm{~h}$ of culture, the cells were assayed for ECM invasion. Data are expressed in terms of percentage of invaded cells with respect to siCTRL/A375 or siCTRL/SK-Mel28 cells treated with DMSO. Each value represents the arithmetic mean \pm SEM of four (A375 and A375R) or three (SK-Mel28 and SK-Mel28R) independent experiments. ${ }^{* *} P<0.01$ siCTRL/DAB vs siCTRL/DMSO; \# $P<0.01$ siPTTG1/DAB vs siPTTG1/DMSO; $\$ P<0.01$ siPTTG1/DMSO vs siCTRL/DMSO; ${ }^{\wedge} P<0.01 \mathrm{siPTTG} 1 / \mathrm{DMSO} v s$ siCTRL/DAB; ${ }^{\dagger} P<0.01 \mathrm{siPTTG1/DAB} v s$ siCTRL/DAB. 
dabrafenib treatment significantly inhibited the ability to invade the ECM. However, invasiveness of dabrafenibtreated CMV-PTTG1/A375 cells was higher than that of drug-treated CMV-EV/A375 cells, in agreement with the finding that former cells expressed PTTG1 levels higher than those of CMV-EV cells.

\section{LEE011 impairs PTTG1 expression, proliferation and invasiveness of A375R cells}

We previously demonstrated that the CDK inhibitor PHA848125 - shown to possess a safety profile and a promising activity against thymic carcinoma in a phase I clinical study [32] - inhibited proliferation of A375 cells, at least in part, through down-regulation of PTTG1 [30]. We, therefore, sought to investigate whether LEE011 (ribociclib), a CDK4/6 inhibitor approved by FDA for breast cancer treatment and under clinical investigation in various type of tumors, including melanoma (www.clinicaltrial.gov), was able to impair PTTG1 expression in A375R cells and whether this molecular event was associated with inhibition of proliferation and invasion and/or modulation of response to dabrafenib.

A375R cells were exposed to DMSO, LEE011 (4 $\mu \mathrm{M}$ or $16 \mu \mathrm{M})$, dabrafenib $(100 \mathrm{nM})$ or a combination of LEE011 ( $4 \mu \mathrm{M}$ or $16 \mu \mathrm{M})$ plus dabrafenib and analyzed for PTTG1 expression, proliferation and ECM invasion 48 $\mathrm{h}$ after drug treatment.

As illustrated in Figure 6 A, PTTG1 expression was reduced in A375R cells treated with $4 \mu \mathrm{M}$ LEE011 and almost abrogated in the cells exposed to $16 \mu \mathrm{M}$ of the drug, either alone or in combination with dabrafenib.

As expected, dabrafenib did not affect proliferation of A375R cells, whereas a concentration-dependent inhibition of cell growth occurred in LEE011-treated cells (Figure 6B). Moreover, the antiproliferative effect of the combinations of LEE011 plus dabrafenib was comparable to that exerted by the corresponding concentrations of LEE011 alone (Figure 6B).

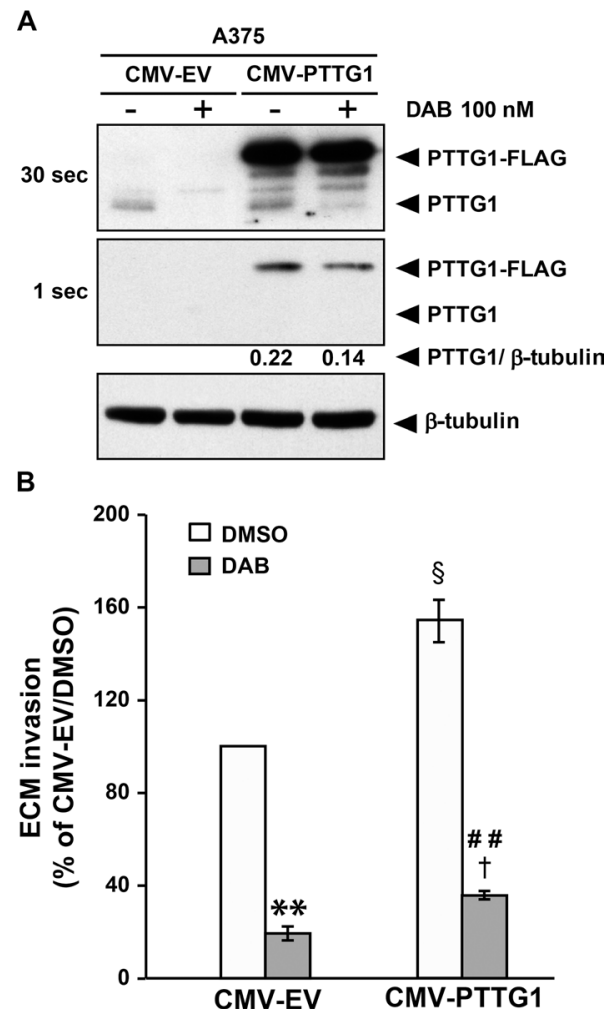

Figure 5: PTTG1 over-expression increases invasiveness of melanoma cells. (A) A375 cells were transiently transfected with CMV-PTTG1 or CMV-EV and $24 \mathrm{~h}$ later exposed to $100 \mathrm{nM}$ dabrafenib (DAB) or DMSO alone (-) for $48 \mathrm{~h}$. Cell lysates were then analyzed by immunoblotting using antibodies against PTTG1 or against $\beta$-tubulin. Two different exposure (30 sec and $1 \mathrm{sec})$ of the same membrane are shown to evidence dabrafenib-induced decrease of both endogenous PTTG1 (PTTG1) and transfected (PTTG1-FLAG) protein in CMV-PTTG1-transfected cells. The ratio between the densitometric level of PTTG1-FLAG and that of $\beta$-tubulin is shown for the $1 \mathrm{sec}$-exposure. The results are representative of three independent experiments. (B) A375 cells were transiently transfected with CMV-PTTG1 or CMV-EV. Twenty-four hours later the cells were incubated with $100 \mathrm{nM}$ dabrafenib (DAB) or DMSO alone and assayed for ECM invasion after $48 \mathrm{~h}$ of culture. Data are expressed in terms of percentage of invaded cells with respect to CMV-EV/A375 cells treated with DMSO. Each value represents the arithmetic mean \pm SEM of three independent experiments. ${ }^{* *} P<0.01 \mathrm{CMV}-\mathrm{EV} / \mathrm{DAB} v s$ CMV-EV/DMSO; ${ }^{\#} P<0.01$ CMV-PTTG1/DAB vs CMV-PTTG1/DMSO; ${ }^{\S} P<0.05$ CMV-PTTG1/DMSO vs CMV-EV/DMSO; ${ }^{\dagger} P<0.05$ CMV-PTTG1/DAB vs CMV-EV/DAB. 
Treatment with $16 \mu \mathrm{M}$ LEE011 significantly impaired the invasive capacity of A375R cells (Figure 6C). A375R cells exposed to dabrafenib in combination with this concentration of LEE011 displayed higher ECM invasion as compared with the cells treated with the CDK inhibitor alone. However, their invasive capacity remained significantly lower than that of the cells exposed to DMSO or to dabrafenib alone (Figure 6C). The lowest concentration of LEE011 failed to reduce basal invasiveness of A375R cells. However, it abrogated upregulation of ECM invasion induced by dabrafenib in this cell line (Figure 6C).

To confirm that the effects of LEE011 on A375R cell proliferation and invasiveness were due, at least in part, to PTTG1 inhibition, the cells were transfected with siCTRL or siPTTG1 and assayed for proliferation and ECM invasion after a $48 \mathrm{~h}$-exposure to DMSO, or $16 \mu \mathrm{M}$ LEE011.

As expected, proliferation of A375R cells was reduced of about $70 \%$ and of about $40 \%$ by LEE 011 treatment and PTTG1 silencing, respectively (Figure 6D). Moreover, the combination of siPTTG1 and LEE011 caused an impairment of cell growth comparable to that produced by LEE011 alone. Consistent with these results, the inhibitory effect of LEE011 on A375R invasiveness was more pronounced than that of siPTTG1 and not enhanced in the cells that had been knocked-down for PTTG1 (Figure 6E).

\section{Down-regulation of MMP-9 secretion is involved in siPTTG1-induced inhibition of A375R cell invasiveness}

It has been previously shown that PTTG1 can promote tumor cell invasiveness by increasing the expression of several effector molecules, including MMP-9 $[21,33,34]$ which has been associated with an invasive phenotype in melanoma $[35,36]$. We therefore decided to investigate whether inhibition of MMP-9 secretion could underlie, at least in part, the inhibitory effects exerted by PTTG1 silencing on the invasive capacity of dabrafenibresistant cells. To this end, A375R cells were transfected with siCTRL or siPTTG1, and assayed for MMP-9 release after a $48 \mathrm{~h}$-exposure to $100 \mathrm{nM}$ dabrafenib or DMSO.

As illustrated in Figure 7A, inhibition of PTTG1 expression alone caused a marked reduction in the amount of MMP-9 released by the cells. In both siCTRL/ A375R and siPTTG1/A375R cells, exposure to dabrafenib increased MMP-9 secretion. However, the amount of MMP-9 released by drug-treated siPTTG1/A375R cells was significantly lower than that of drug-treated siCTRL/ A375R cells and comparable to that of siCTRL/A375R cells exposed to DMSO.

A375R cells were then incubated with $100 \mathrm{nM}$ dabrafenib or DMSO and after $48 \mathrm{~h}$ of culture assayed for ECM invasion in the presence of an anti-MMP-9 mAb, or of a control antibody. Both DMSO-treated and dabrafenibtreated cells displayed a significant inhibition of ECM invasion when assayed in the presence of the anti-MMP-9 $\mathrm{mAb}$ (Figure 7B).

We next evaluated the effect of the anti-MMP-9 $\mathrm{mAb}$ on the invasive capacity of siCTRL/A375R and siPTTG1/A375R cells exposed to $100 \mathrm{nM}$ dabrafenib or DMSO for $48 \mathrm{~h}$.

With reference to the cells treated with DMSO alone, the results presented in Figure $7 \mathrm{C}$ show that the invasive capacity of siPTTG1/A375R cells assayed in the presence of the control antibody was comparable to that of siCTRL/A375R cells tested in the presence of the anti-MMP-9 mAb. Moreover, no further inhibition of ECM invasion occurred when siPTTG1/A375R cells were assayed in the presence of the anti-MMP-9 mAb (Figure 7C). These findings support the hypothesis that PTTG1 silencing impairs invasiveness of A375R cells through a down-regulation of MMP-9 levels.

In all instances, the invasive capacity of dabrafenibtreated cells was higher than that of the corresponding DMSO-treated counterparts (Figure 7C). Consistent with the results obtained with the cells exposed to DMSO alone, dabrafenib-treated cells subjected to either PTTG1 silencing or to MMP-9 neutralization or to both conditions displayed a comparable level of ECM invasion. This was significantly reduced with respect to that of dabrafenibtreated siCTRL/A375R cells and comparable to that of DMSO-treated siCTRL/A375R cells, both assayed in the presence of the control antibody (Figure 7C).

\section{Evaluation of PTTG1 plasma levels in melanoma patients subjected to therapy with dabrafenib, vemurafenib or dabrafenib plus trametinib}

Previous studies by Wang et al. [37] demonstrated that the PTTG1 protein could be detected in peripheral blood from non-cancer patients and to a significantly higher extent in peripheral blood from patients with colorectal neuroendocrine tumor. We therefore carried out a preliminary investigation to evaluate whether the PTTG1 protein was present also in plasma of melanoma patients and whether changes in PTTG1 levels, possibly related to clinical response, could occur during therapy with BRAFi (dabrafenib or vemurafenib) or the combination of dabrafenib plus trametinib. The study was conducted on a total of 22 patients from whom plasma samples collected before the start of the therapy (T0), after two months of treatment (T2) and at disease progression (TP) were already available.

Among the 22 patients, 11 were subjected to dabrafenib or vemurafenib monotherapy, whereas 3 were treated with dabrafenib alone for 8,5 or 4 months and then with dabrafenib plus trametinib. The remaining patients were subjected to the combination of dabrafenib plus trametinib (Table 2). Five patients experienced disease 
A

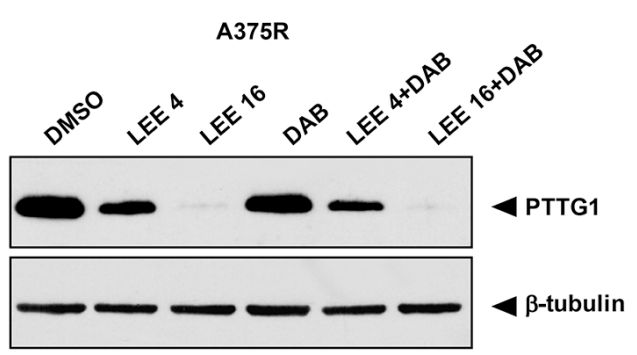

B

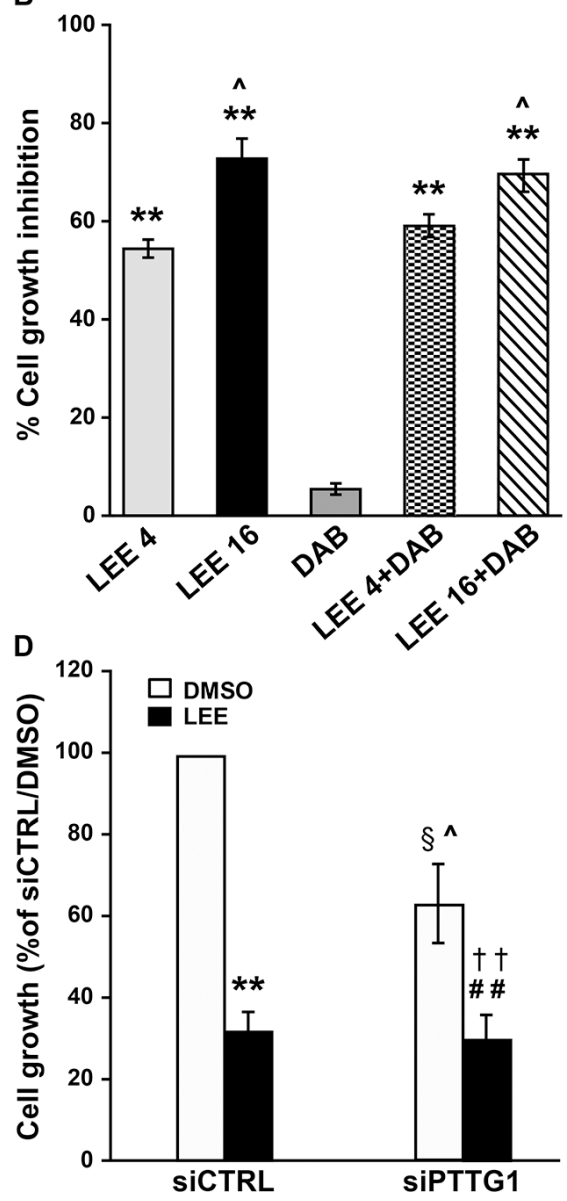

C
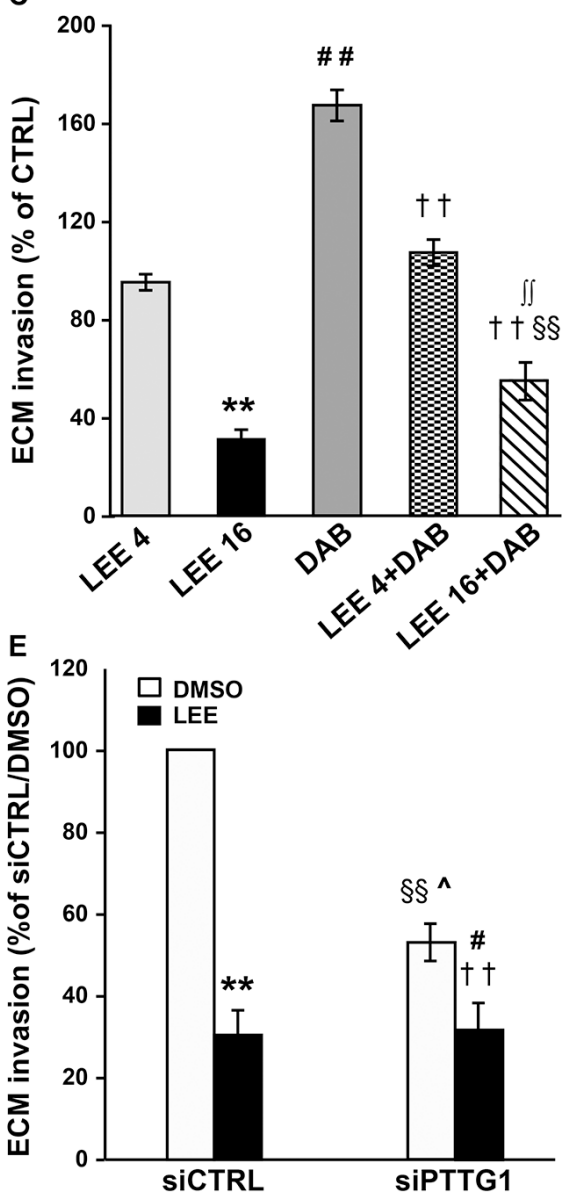

Figure 6: LEE011 reduces PTTG1 expression, invasiveness and proliferation in A375R cells. (A) A375R cells were incubated with DMSO alone, $4 \mu \mathrm{M}$ LEE011 (LEE 4), $16 \mu \mathrm{M}$ LEE011 (LEE 16), $100 \mathrm{nM}$ dabrafenib (DAB) or a combination of dabrafenib plus $4 \mu \mathrm{M}$ or $16 \mu \mathrm{M}$ LEE011 for $48 \mathrm{~h}$ and then cell lysates were analyzed by immunoblotting using antibodies against PTTG1 or against $\beta$-tubulin. The results are representative of three independent experiments. (B) A375R cells were treated as described in (A) and then recovered and counted. Data are expressed in terms of percentage of cell growth inhibition of drug-treated cells with respect to cells treated with DMSO alone. Each value represents the arithmetic mean of four independent experiments. Bars, SEM. ${ }^{* *} P<0.01$ drug-treated cells $v s$ DMSO-treated cells. ${ }^{\wedge} P<0.0516 \mu \mathrm{M}$ LEE011 vs $4 \mu \mathrm{M}$ LEE011 and DAB+16 $\mu \mathrm{M}$ LEE011 vs DAB+4 $\mu \mathrm{M}$ LEE011. (C) A375R cells were treated as described in (A) and then assayed for ECM invasion. Data are expressed in terms of percentage of invaded cells with respect to A375R cells treated with DMSO (CTRL). Each value represents the arithmetic mean \pm SEM of four independent experiments. ${ }^{* *} P<$ 0.01 LEE 16 vs DMSO; ${ }^{\#} P<0.01$ DAB $v s$ DMSO; ${ }^{\S} P<0.01$ LEE 16+DAB $v s$ DMSO; ${ }^{\dagger} P<0.01$ LEE 4+DAB and LEE 16+DAB $v s$ DAB; ${ }^{\int} P<0.01$ LEE $16+\mathrm{DAB} v s$ LEE 16. (D) A375R cells were transiently transfected with siPTTG1 or siCTRL and $24 \mathrm{~h}$ later incubated with DMSO alone or $16 \mu \mathrm{M}$ LEE011 (LEE). After $48 \mathrm{~h}$ of culture, the cells were recovered and counted. Data are expressed in terms of percentage of growth with respect to siCTRL/A375R cells treated with DMSO. Each value represents the arithmetic mean $\pm \mathrm{SEM}$ of three independent experiments. ${ }^{* *} P<0.01$ siCTRL/LEE $v s$ siCTRL/DMSO; ${ }^{\#} P<0.01$ siPTTG1/LEE $v s$ siPTTG1/DMSO; ${ }^{\circledR} P<0.05$ siPTTG1/ DMSO $v s$ siCTRL/DMSO; ${ }^{\wedge} P<0.05$ siPTTG1/DMSO $v s$ siCTRL/LEE; ${ }^{\dagger} P<0.01$ siPTTG1/LEE $v s$ siCTRL/DMSO. (E) A375R cells were transfected and treated and indicated in (D). After $48 \mathrm{~h}$ of culture, the cells were assayed for ECM invasion. Data are expressed in terms of percentage of invaded cells with respect to siCTRL/A375R cells treated with DMSO. Each value represents the arithmetic mean \pm SEM of three independent experiments. ${ }^{* *} P<0.01$ siCTRL/LEE $v s$ siCTRL/DMSO; ${ }^{*} P<0.05$ siPTTG1/LEE $v s$ siPTTG1/DMSO; $\$$ $P$ $<0.01$ siPTTG1/DMSO $v s$ siCTRL/DMSO; ${ }^{\wedge} P<0.05$ siPTTG1/DMSO $v s$ siCTRL/LEE; ${ }^{\dagger} P<0.01$ siPTTG1/LEE $v s$ siCTRL/DMSO. 
progression within 2 months from the start of therapy, whereas 1 patient had stable disease for 5 months and then underwent progression (Table 2). These patients were included in the group of "non-responders" and only T0 and T2 plasma samples were considered for the analysis. The remaining patients experienced partial response as evaluated by computer tomography after 3 months of therapy (Table 2), and constituted the group of "responders". Among the 60 plasma samples tested, 18 displayed PTTG1 levels under the lower limit of ELISA detection (T0, $n=7$; T2, $n=8$; TP, $n=3$ ).

Among the responder patients, 2 (case \#13 and case \#14) displayed PTTG1 plasma levels below the limit of assay detection at all the three time points analyzed,
A

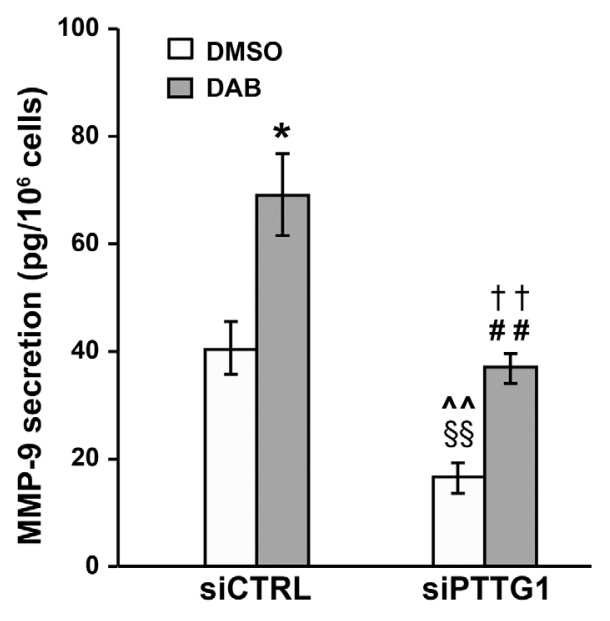

B

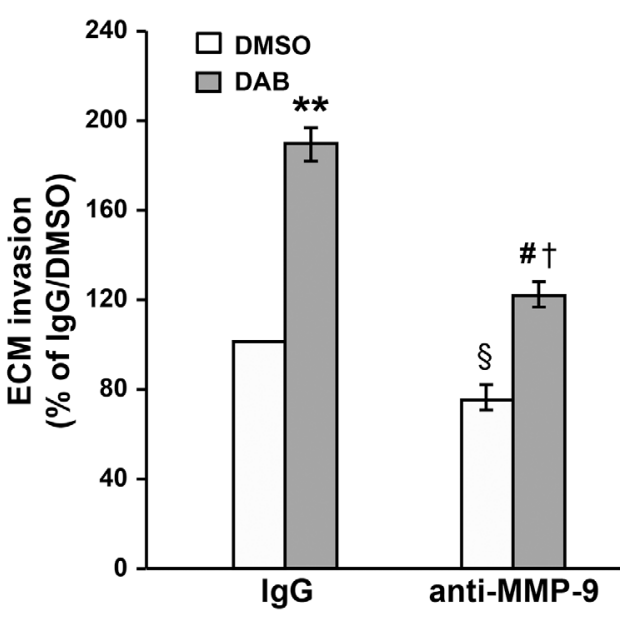

C

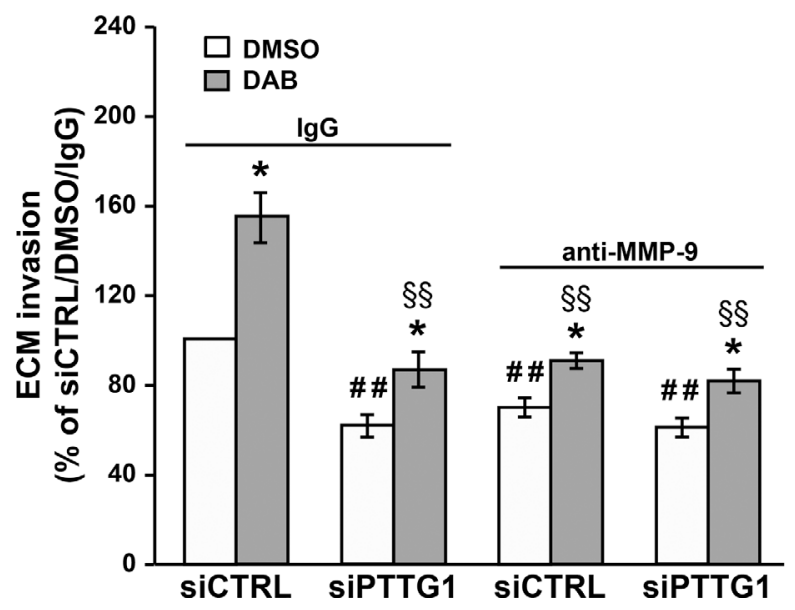

Figure 7: Inhibition of MMP-9 secretion contributes to the impairment of A375R cell invasiveness induced by PTTG1 silencing. (A) A375R cells were transiently transfected with siPTTG1 or siCTRL and $24 \mathrm{~h}$ later incubated with $100 \mathrm{nM}$ dabrafenib (DAB) or DMSO alone. After $48 \mathrm{~h}$ of drug exposure, the amount of MMP-9 in the culture supernatants was determined by ELISA. Each value

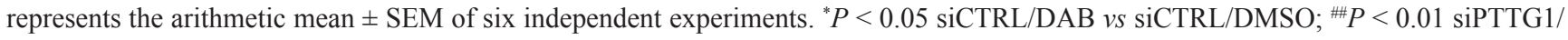
DAB $v s$ siPTTG1/DMSO; ${ }^{\$} P<0.01$ siPTTG1/DMSO $v s$ siCTRL/DMSO; ${ }^{\wedge} P<0.01$ siPTTG1/DMSO $v s$ siCTRL/DAB; ${ }^{\dagger} P<0.01$ siPTTG1/DAB vs siCTRL/DAB. (B) A375R cells were treated with $100 \mathrm{nM}$ dabrafenib (DAB) or DMSO alone for $48 \mathrm{~h}$ and then assayed for their ability to invade the ECM in the presence of an anti-MMP-9 mAb or a control antibody (IgG). Data are expressed in terms of percentage of invaded cells with respect to A375R cells treated with DMSO and assayed in the presence of the control antibody. Each value represents the arithmetic mean \pm SEM of three independent experiments. ${ }^{* *} P<0.01 \mathrm{DAB} / \mathrm{IgG}$ vs DMSO/IgG; ${ }^{\#} P<0.05 \mathrm{DAB} /$ anti-MMP-9 vs DMSO/anti-MMP-9; ${ }^{\S} P<0.05$ DMSO/anti-MMP-9 vs DMSO/IgG; ${ }^{\dagger} P<0.05$ DAB/anti-MMP-9 vs DAB/IgG. (C) A375R cells were transiently transfected with siPTTG1 or siCTRL and $24 \mathrm{~h}$ later incubated with $100 \mathrm{nM}$ dabrafenib (DAB) or DMSO alone. After $48 \mathrm{~h}$ of drug exposure, the cells were assayed for their ability to invade the ECM in the presence of an anti-MMP-9 mAb or a control antibody (IgG). Each value represents the arithmetic mean \pm SEM of three independent experiments. ${ }^{*} P<0.05$ dabrafenib-treated cells $v s$ matched DMSO-treated cells; ${ }^{\#} P<0.01$ siPTTG1/IgG/DMSO, siCTRL/MMP-9/DMSO, siPTTG1/MMP-9/DMSO vs siCTRL/IgG/DMSO; ${ }^{\S} P<$ $0.01 \mathrm{siPTTG1/IgG/DAB,} \mathrm{siCTRL/MMP-9/DAB,} \mathrm{siPTTG1/MMP-9/DAB} \mathrm{vs} \mathrm{siCTRL/IgG/DAB.}$ 
Table 2: Demographics and clinical characteristics of melanoma patients from whom plasma was collected

\begin{tabular}{lccccccc}
\hline $\begin{array}{l}\text { Patient } \\
\text { case }\end{array}$ & Sex & $\begin{array}{c}\text { Age } \\
\text { (years) }\end{array}$ & Stage $^{\mathbf{a}}$ & Previous therapy & Targeted therapy $^{\mathbf{b}}$ & Response $^{\mathbf{c}}$ & TTF (days) $^{\mathbf{d}}$ \\
\hline 1 & $\mathrm{~F}$ & 45 & M1c & None & DAB (8) $\rightarrow$ COMBO & PR & 1324 \\
2 & $\mathrm{~F}$ & 48 & M1c & Fotemustine & DAB & PR & 182 \\
3 & M & 38 & M1c & None & DAB & PR & 144 \\
4 & F & 64 & M1b & None & COMBO & PR & 234 \\
5 & M & 71 & M1c & None & DAB (5) $\rightarrow$ COMBO & PR & 1275 \\
6 & M & 43 & M1c & None & DAB & SD & - \\
7 & M & 47 & M1c & Fotemustine & DAB & PR & 147 \\
8 & M & 66 & M1a & None & DAB (4) $\rightarrow$ COMBO & CR & 488 \\
9 & F & 82 & M1c & Dacarbazine & VEMU & PD & - \\
10 & M & 81 & M1c & None & VEMU & PD & - \\
11 & M & 57 & M1c & None & VEMU & PR & 223 \\
12 & M & 60 & M1b & None & COMBO & PR & 1082 \\
13 & M & 45 & M1c & None & COMBO & PR & 188 \\
14 & M & 70 & M1c & None & COMBO & PR & 117 \\
15 & M & 65 & M1c & None & VEMU & PD & - \\
16 & M & 49 & M1c & None & VEMU & PR & 147 \\
17 & M & 39 & M1b & None & DAB & PD & - \\
18 & M & 81 & M1c & None & VEMU & PD & - \\
19 & F & 46 & M1c & None & COMBO & PR & 244 \\
20 & M & 56 & M1c & Nivolumab & COMBO & PR & 504 \\
21 & M & 57 & M1c & None & COMBO & PR & 172 \\
22 & M & 35 & M1c & None & COMBO & PR & 180 \\
\hline
\end{tabular}

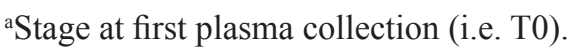

${ }^{b} \mathrm{DAB}$, dabrafenib. In parenthesis, months of monotherapy before trametinib addiction. COMBO, dabrafenib + trametinib. VEMU, vemurafenib.

${ }^{\mathrm{C}}$ Clinical response as evaluated three months after therapy commencement. PR, partial response; SD, stable disease; PD, progressive disease.

dTTF, time to treatment failure.

whereas the remaining patients had at least one time point with measurable PTTG1 level. The amount of PTTG1 in plasma of these patients at the different time points analyzed is illustrated in Figure 8A. A decrease of circulating PTTG1 was observed at T2 in 8 out of $11(73 \%)$ responder patients with detectable T0-PTTG1 levels. In 6 of these patients, PTTG1 plasma levels rose again at TP. An increase in circulating PTTG1 at TP as compared with $\mathrm{T} 2$ was also observed in 2 patients with no measurable PTTG1 at T0 and in 1 patient with comparable PTTG1 levels at T0 and T2.

Among the non-responder patients, 1 (case \#18) had both T0 and T2 levels under the limit of the assay, 1 displayed reduced PTTG1 levels at T2, while the remaining patients (67\%) did not show significant changes in plasma PTTG1 levels between the two time points investigated (Figure 8B).
Figure 9 shows the results of statistical analyses performed on PTTG1 plasma levels detected at the different time points in all responder and non-responder patients. At baseline (T0), no significant differences were observed in PTTG1 levels between responder and non-responder group. The median PTTG1 levels at baseline was $0.35 \mathrm{ng} / \mathrm{mL}(\mathrm{IQR}=0.01,1.05)$ for the responders group and $0.60 \mathrm{ng} / \mathrm{mL}(\mathrm{IQR}=0.01,0.98)$ for non-responders $(P=0.89)$. Compared to T0, a considerable decrease in PTTG1 level was observed at $\mathrm{T} 2$ in responders (median $0.12 \mathrm{ng} / \mathrm{mL} ; \mathrm{IQR}=0.01$, $0.67)$ even though the T0-T2 comparison did not reach the statistical significance $(P=0.11)$. A statistically significant increase of PTTG1 levels was observed at $\mathrm{TP}$ in comparison with T2, with a median level of 0.42 $\mathrm{ng} / \mathrm{mL}(\mathrm{IQR}=0.21,1.68)(P<0.05)$. In non-responder patients, PTTG1 levels at T2 were similar to baseline 
levels, with a median level of $0.50 \mathrm{ng} / \mathrm{mL}(\mathrm{IQR}=0.01$, 0.85) $(P=0.83)$.

\section{DISCUSSION}

Cutaneous melanoma is an aggressive cancer that causes the greatest number of skin cancer-related deaths worldwide. While early-stage melanoma can be cured successfully by surgical resection, patients with metastatic melanoma have a poor prognosis, with a median survival rate of less than 1 year and a 5 -year survival rate of less than 5\% [38]. Monotherapy with BRAFi and combined therapy with BRAFi and MEKi possess remarkable clinical activity in patients with metastatic BRAFmutant melanoma - yielding objective response rates of $50-60 \%$ and of $65-75 \%$, respectively - and significantly prolong progression-free and overall survival [39-41]. However, drug resistance eventually, and often rapidly, emerges, limiting the long-term efficacy of the targeted therapy [42-44]. In addition, most responses are partial and about $10-20 \%$ of patients show primary resistance.
Novel therapeutic approaches able to improve response to BRAFi and MEKi and to mitigate or overcome acquired resistance, as well as biomarkers to predict and/or monitor response to therapy, are therefore urgently needed.

In this study we investigated the involvement of PTTG1 in the regulation of proliferation and invasiveness of melanoma cells sensitive or resistant to dabrafenib and whether targeting PTTG1 could affect the response of those cells to the BRAFi. We also performed a preliminary study to explore the potential value of PTTG1 plasma level to monitor patient response to treatment with BRAFi, alone or in combination with MEKi.

\section{Dabrafenib-sensitive cells}

Our results show that in the dabrafenib-sensitive cell lines A375 and SK-Mel28, PTTG1 silencing markedly inhibited ECM invasion. Moreover, proliferation of both cell lines was strongly reduced six days after siPTTG1 transfection. A significant inhibition of cell growth was evident in A375 but not SK-Mel28 cells after three days of PTTG1 silencing, most probably because of the

\section{A}
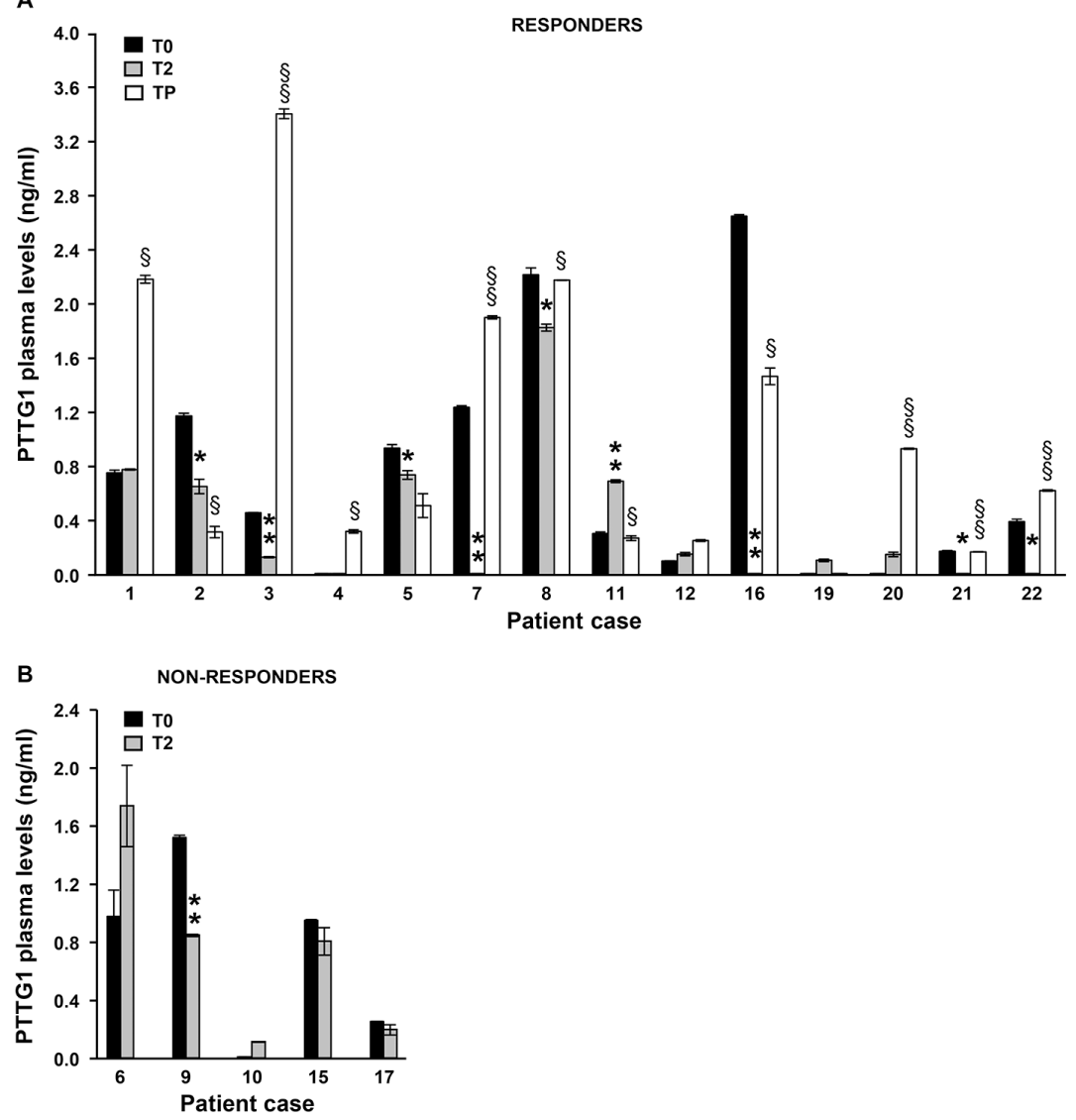

Figure 8: Quantification of PTTG1 protein in plasma of melanoma patients treated with BRAFi or the combination of dabrafenib plus trametinib. PTTG1 levels were determined by ELISA in plasma samples of 16 responder (A) and 6 non-responder (B) melanoma patients before the start of therapy (T0), after two months of treatment (T2) and at disease progression (TP). Two patients among responders (case \#13 and case \#14) and 1 patient among non-responder (case \#18) displayed PTTG1 plasma levels below the detection limit of the assay at all the time points analyzed and were not included in the figures. Each value represents the arithmetic mean $\pm \mathrm{SEM}$ of two independent determinations. ${ }^{* *} P<0.01$ and ${ }^{*} P<0.05 \mathrm{~T} 2$ vs $\mathrm{T} 0 ;{ }^{\S} P<0.01$ and ${ }^{\S} P<0.05 \mathrm{TP} v s \mathrm{~T} 2$. 
higher proliferative rate of A375 cells as compared with SK-Mel28 cells. Notably, over-expression of PTTG1 in A375 cells promoted invasiveness but not proliferation, suggesting that the basal level of PTTG1, which in those cells is markedly up-regulated as compared with normal melanocytes [30], is already sufficient to maximally support cell growth.

In the drug-sensitive cell lines, dabrafenib treatment abrogated PTTG1 expression and this molecular event appears to contribute to the suppressive effects exerted by the drug on cell ability to invade the ECM. Indeed, as stated above, PTTG1 silencing alone was able to impair invasiveness of A375 and SK-Mel28 cells. Moreover, in both cell lines, dabrafenib-induced inhibition of ECM invasion was not affected by PTTG1 silencing, as expected being the drug able to suppress PTTG1 expression by itself. Noteworthy, the impairment of ECM invasion caused by PTTG1 knock-down was lower than that produced by dabrafenib, indicating that beside PTTG1 expression, additional pathways involved in melanoma cell invasiveness are inhibited by this drug. Accordingly, the invasive capacity of A375 cells over-expressing PTTG1 was still markedly reduced by dabrafenib, even though it was significantly higher than that displayed by dabrafenib-treated control cells.

The influence of PTTG1 expression level on the growth suppressive effects of dabrafenib appears to be more dependent on the cell context, since in A375 cells neither PTTG1 silencing nor PTTG1 over-expression altered sensitivity to dabrafenib, whereas PTTG1 knockdown increased drug sensitivity of SK-Mel28 cells, as evidenced by MTT assays performed after five days of exposure to dabrafenib. The molecular mechanisms underlying this different behavior of A375 and SK-Mel28 cells remain, however, to be ascertained. In agreement with the finding that several antitumor agents negatively modulate PTTG1 expression through p53 activation [24, 45], we previously demonstrated that the CDK inhibitor PHA-848125 markedly impaired PTTG1 expression and proliferation in melanoma cells endowed with wildtype p53, whereas in p53-mutated cells the drug did not substantially affect the levels of this protein and inhibited proliferation to a lesser extent [30]. Accordingly, PTTG1 silencing increased PHA-848125 sensitivity only in p53mutated cells, being these cells unable to undergo a p53mediated reduction of PTTG1 upon exposure to PHA848125 alone [30]. A375 cells are p53 wild-type, whereas SK-Mel28 cells express a mutant form of p53 [46]. However, in both A375 and SK-Mel28 cells dabrafenib equally impaired PTTG1 expression. Therefore, the different p53 status of A375 and SK-Mel28 cells does not explain why siPTTG1 increased dabrafenib sensitivity only in SK-Mel28 cells. On the other hand, PTTG1 interact with numerous proteins and, as a transcription factor, it can directly or indirectly regulate the expression of hundreds of genes involved in cell cycle, apoptosis,

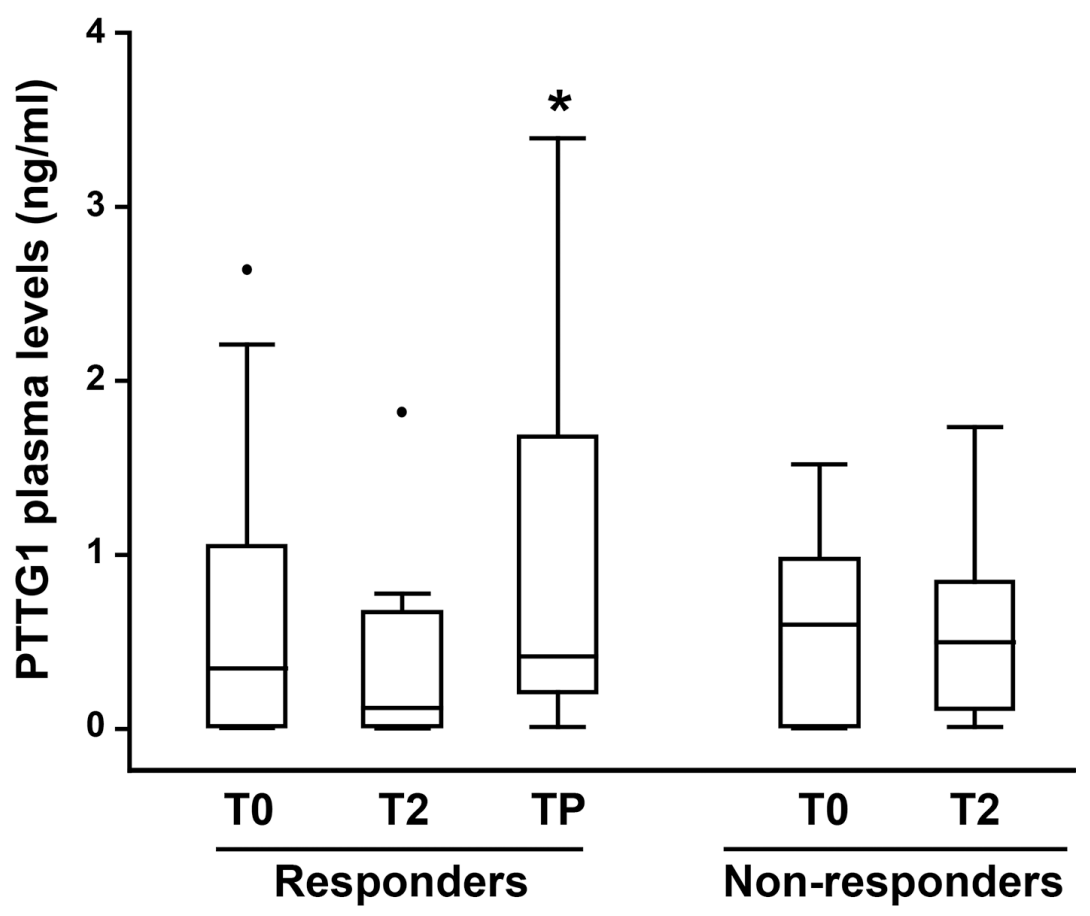

Figure 9: Box-and-whisker diagrams of PTTG1 plasma levels in melanoma patients treated with BRAFi or the combination of dabrafenib plus trametinib. PTTG1 plasma levels were measured in 22 melanoma patients (16 responders and 6 non-responders) before therapy commencement (T0), after two months of treatment (T2) and at disease progression (TP). The edges of each box represent the 75th and 25th percentile, respectively, and whiskers the maxima and minima. The horizontal bar within each box indicates the median. The outliers are denoted by dots. Data were analysed by nonparametric Wilcoxon matched-pairs signed-rank test; ${ }^{*} P<0.05$ TP vs T2. 
metabolism and signal transduction [1-4]. It is possible to speculate that differences in the expression/mutational status of PTTG1 targets between A375 and SK-Mel28 cells could be responsible for their different response to dabrafenib after siPTTG1 transfection.

Previous investigations performed in cellular models different from melanoma, point out that PTTG1 expression can be regulated by multiple mechanisms. Actually, transcription of the PTTG1 gene was found to be directly activated by the transcription factors SP1, NF-Y, Oct-1 and T-cell factor 4, and, as stated above, suppressed by p53 [1, 4]. Positive regulation of PTTG1 expression was also demonstrated for several growth factors, including epidermal growth factor, hepatocyte growth factor, fibroblast growth factor-2, insulin-like growth factor-1, which are known to activate mitogen-activated protein kinase (MAPK) and phosphatidylinositol 3-kinase signaling pathways [1, 2, 4]. More recently, several microRNAs have also emerged as negative regulators of PTTG1 expression [8, 11, 13, 19, 47, 48]. Interestingly, Hernandez et al. [49] demonstrated that dicumarol downregulated PTTG1 expression in HCT116 colon cancer cells at least in part through inhibition of Hsp90 and the consequent impairment of the RAS/RAF/MEK/ERK signaling pathway. Although further studies are required to identify the mechanisms underlying dabrafenib-induced inhibition of PTTG1 expression, it is reasonable to hypothesize that drug-induced impairment of the BRAF/ $\mathrm{MEK} / \mathrm{ERK}$ signaling cascade contributes to this molecular event.

\section{Dabrafenib-resistant cells}

In this study we analyzed two cell lines with acquired resistance to dabrafenib, namely A375R and SK-Mel28R. With respect to their matched drugsensitive counterpart, both cell lines displayed increased invasiveness and secreted higher amount of VEGF-A and MMP-9. On the other hand, they responded differently to a short term exposure to dabrafenib, which induced a further increase of VEGF-A and MMP-9 secretion and of ECM invasion in A375R cells, whereas it did not affect these cellular processes in SK-Mel28R cells. Noteworthy, the basal levels of VEGF-A and MMP-9 secretion in SK-Mel28R cells were about 5-fold and 2-fold higher, respectively, than those detected in A375R cells. Moreover, we previously demonstrated that in A375R cells, dabrafenib-induced stimulation of ECM invasion was dependent on drugmediated up-regulation of VEGF-A secretion [31]. The high amount of VEGF-A and MMP-9 produced by SKMel28R cells themselves, could explain why the release of these cytokines did not increase when the cells were exposed to dabrafenib and why no further stimulation of ECM invasion was induced by either exogenous VEGF-A or dabrafenib treatment.
The increased invasiveness of A375R and SKMel28R cells does not appear to be dependent on upregulation of PTTG1 expression, as both cell lines expressed PTTG1 at levels comparable to those of their matched drug-sensitive counterparts. Nevertheless, the invasive capacity of A375R and SK-mel28R cells was markedly reduced by PTTG1 knock-down. Moreover, although dabrafenib still stimulated invasiveness in PTTG1-silenced A375R cells, ECM invasion by those cells was significantly reduced as compared to that of drug-treated PTTG1-expressing cells. In the clinical setting, melanoma patients developing resistance to BRAFi frequently continue treatment beyond progression. Indeed, it has been demonstrated that prolonging BRAFi therapy beyond RECIST disease progression can provide a clinical benefit $[50,51]$. Our findings suggest that targeting PTTG1 in combination with dabrafenib therapy could provide a better disease control, being the impairment of PTTG1 expression able to reduce cell proliferation, restrain the highly invasive behavior associated with acquired resistance to dabrafenib and to counteract possible stimulating effects of the drug on melanoma cell metastatic potential. In this regard, our data show that treatment with the CDK4/6 inhibitor LEE011 at the concentration of $4 \mu \mathrm{M}$, which corresponds approximately to the mean value of the peak plasma concentration observed in patients treated with the drug at the dose of $600 \mathrm{mg} /$ day 3-weeks-on/1-week-off [52] was able to reduce PTTG1 levels in A375R cells. Notably, exposure to $4 \mu \mathrm{M}$ LEE011 caused a significant inhibition of A375R cell proliferation that was maintained also when the CDK4/6 inhibitor was given in combination with dabrafenib. Moreover, although $4 \mu \mathrm{M}$ LEE011 did not affect A375R basal invasiveness, it abrogated stimulation of ECM invasion induced by dabrafenib in this cell line.

The effects of LEE011 on proliferation and invasiveness of A375R cells were even more pronounced when the drug was used at the concentration of $16 \mu \mathrm{M}$, which abrogated PTTG1 expression. Indeed, $16 \mu \mathrm{M}$ LEE011 not only was more effective than $4 \mu \mathrm{M}$ LEE011 in reducing A375R cell proliferation, but markedly inhibited basal invasiveness of these cells. Moreover, although the invasive capacity of A375R cells treated with dabrafenib plus $16 \mu \mathrm{M}$ LEE011 was higher than that displayed by the cells treated with the CDK4/6 inhibitor alone, it still remained lower than that of DMSO-treated cells. These results suggest that inhibition of PTTG1 expression induced by LEE011 contributed in part to druginduced impairment of cell proliferation and invasiveness. Accordingly, comparable reduction of cell growth and ECM invasion was observed in control and PTTG1silenced A375R cells upon treatment with $16 \mu \mathrm{M}$ LEE011.

CDK4/6 inhibitors represent promising candidates for cancer therapy (reviewed in [53-55]), since alterations in the cyclin D-CDK4/6-p16 $6^{\mathrm{INK} 4 \mathrm{~A}}-\mathrm{Rb}$ pathway occur frequently in various type of tumors, including the 
majority of melanomas, and promote continued growth. Actually, palbociclib and LEE011 have been approved by FDA for breast cancer treatment. Moreover, the two drugs and other CDK4/6 inhibitors are under clinical investigation as single agents or in combination therapy in a range of tumors (www.clinicaltrial.gov).

Although CDK4/6 inhibitors can reduce melanoma cells growth both in vitro and in animal models, the effects of these drugs appear to be mainly cytostatic [53, 55]. Therefore, monotherapy with CDK4/6 inhibitors is not considered an effective treatment modality in melanoma. On the other hand, synergistic or additive antiproliferative effects of concomitant inhibition of CDK4/6 and the MAPK pathway have been shown in melanoma cells [53, 55, 56]. Moreover, Yadav et al. [56] demonstrated that the CDK4/6 inhibitor LY2835219 was highly effective in suppressing, both in vitro and in vivo, the growth of melanoma cells with acquired resistance to the BRAFi vemurafenib. Our results are consistent with those previous findings. Moreover, they demonstrate that CDK4/6 inhibitors can also reduce invasiveness of BRAFi-resistant cells and counteract possible stimulating effects of BRAFi on the invasive capacity of those cells, thus providing further experimental support to therapeutic strategies combining inhibitors of the MAPK pathway with drugs selectively targeting CDK4/6.

In the present study, we also investigated whether down-regulation of MMP-9 secretion could be involved in the impairment of ECM invasion caused by PTTG1 knock-down in dabrafenib-resistant cells. Actually, MMP9 plays an important role in melanoma invasion $[35,36]$ and PTTG1 has been shown to positively regulate the expression levels of MMP-9 [21, 33, 34].

Our data strongly support the involvement of MMP9 down-regulation in the effects of PTTG1 silencing on invasiveness of dabrafenib-resistant cells. Indeed, PTTG1 knock-down in A375R cells before exposure to either DMSO or dabrafenib significantly reduced MMP-9 secretion. Moreover, the invasive capacity of control and drug-treated cells resulted inhibited when assayed in the presence of an anti-MMP-9 mAb. Finally, in both DMSOand dabrafenib-treated cells, PTTG1 silencing, MMP-9 inhibition or their combination induced comparable levels of inhibition of ECM invasion.

\section{Changes of PTTG1 plasma levels in melanoma patients subjected to targeted therapy}

The PTTG1 protein has been reported to be detectable in plasma of healthy subjects and patients with colorectal neuroendocrine tumor [37]. Therefore, the finding that upon exposure to dabrafenib PTTG1 expression was markedly impaired only in melanoma cells sensitive to the drug and that this molecular event contributed to dabrafenib-induced inhibition of cell proliferation and invasiveness, prompt us to conduct an exploratory study to assess whether the PTTG1 protein could be detected also in plasma of melanoma patients and whether changes in circulating PTTG1 levels occurred during targeted therapy and were related to patient response.

Even if limited by the small number of patients examined, our preliminary investigation provides interesting findings. Indeed, it demonstrates that the PTTG1 protein was present in plasma of a considerable proportion of melanoma patients even though in different amounts. The study also shows that after two months of therapy, a decrease of circulating PTTG1 occurred in about $70 \%$ of responder patients with detectable baseline levels of the protein, and that in $60 \%$ of these patients PTTG1 levels rose again at disease progression. In contrast, in only 1 patient among the non-responder group a reduction of plasma PTTG1 was observed at T2. Although it remains to be ascertain whether the decrease of circulating PTTG1 in responder patients simply reflects the reduction of tumor burden or is also due to drug-induced down-regulation of PTTG1 expression in melanoma cells, these findings are consistent with and reinforce our in vitro results. However, it must be pointed out that when responder patients were considered in their whole number, the T2-TP but not the T0-T2 PTTG1 comparison reached the statistical significance, most probably as a result of the low number of patients examined. Therefore, although our data suggest that monitoring circulating PTTG1 during therapy with BRAFi or BRAFi plus MEKi might provide useful information about patient response, this need to be confirmed in a larger study, that was beyond the scope of the present investigation.

\section{CONCLUSIONS}

Our results provide evidence that PTTG1 is involved in the positive regulation of melanoma cell proliferation and invasiveness. They also demonstrate that in dabrafenib-sensitive cells, inhibition of cell growth and ECM invasion caused by this drug occur at least in part, through down-regulation of PTTG1 expression. More important, our study shows that in dabrafenib-resistant cells, inhibition of PTTG1 expression efficiently impairs proliferation and invasiveness, suggesting that in patients progressing on dabrafenib therapy, PTTG1 targeting, alone or in combination with BRAFi, could represent a useful strategy to control tumor growth and metastatic spreading. Finally, we present preliminary evidences that circulating PTTG1 might represent a novel biomarker to monitor patient response to targeted therapy.

\section{MATERIALS AND METHODS}

\section{Cell cultures}

The human melanoma cell lines A375 and SKMel28 were purchased from the European Collection 
of Cell Cultures (Salisbury, UK) and American Type Culture Collection (ATCC, Manassas, VA) respectively. The cells were cultured in BioWhittaker ${ }^{\mathrm{TM}}$ RPMI-1640 medium (LONZA, Verviers, Belgium) supplemented with $10 \%$ fetal bovine serum (Sigma-Aldrich, St. Louis, MO), $2 \mathrm{mM}$ BioWhittaker ${ }^{\mathrm{TM}}$ L-glutamine (LONZA), and $50 \mu \mathrm{g} / \mathrm{ml}$ BioWhittaker ${ }^{\mathrm{TM}}$ gentamicin (LONZA) (hereafter referred to as complete medium, CM). The dabrafenib-resistant A375R cell line, generated in our laboratory, has been previously described [31]. The dabrafenib-resistant SK-Mel28R cell line was generated in the present study by growing the parental SK-Mel28 cells in gradually increasing concentrations of dabrafenib (from $1 \mathrm{nM}$ up to $1.5 \mu \mathrm{M}$ ), as previously reported for the generation of the A375R cell line. A375R and SKMel28R cell lines were maintained in CM supplemented with $1.5 \mu \mathrm{M}$ dabrafenib.

\section{Drugs, chemicals and antibodies for Western blot analysis}

Dabrafenib (GSK2118436A) and LEE011 (Active Biochem, Hong Kong) were dissolved in DMSO (SigmaAldrich) at a final concentration of $1.92 \mathrm{mM}$ and $16 \mathrm{mM}$, respectively. Drugs were stored as stock solutions at $-80^{\circ} \mathrm{C}$ and diluted in $\mathrm{CM}$ just before use.

3-(4,5-dimethylthiazol-2-yl)-2,5-diphenyltetrazolium bromide (MTT) was purchased from Sigma-Aldrich, dissolved at a concentration of $5 \mathrm{mg} / \mathrm{ml}$ in $\mathrm{GIBCO}^{\mathrm{TM}}$ Phosphate-Buffered Saline (PBS) (Invitrogen, Thermo Fisher Scientific, Waltham, MA) and stored at $4^{\circ} \mathrm{C}$.

Mouse monoclonal antibody (mAb) against PTTG1 (DCS-280) and rabbit polyclonal antibody against human $\beta$-tubulin (sc-9104) were purchased from Santa Cruz Biotechnology, Inc., (Santa Cruz, CA).

Reagents for sodium dodecyl sulphate (SDS)polyacrylamide gel electrophoresis were all purchased from Bio-Rad Laboratories, Inc. (Hercules, CA).

\section{Chemosensitivity assay}

Melanoma cells were suspended in CM, seeded $\left(50 \mu \mathrm{l} /\right.$ well) into BD Falcon ${ }^{\mathrm{TM}}$ 96-well plates (BD Biosciences, Bedford, MA) and allowed to adhere at $37^{\circ} \mathrm{C}$ in a $5 \% \mathrm{CO}_{2}$ atmosphere for $18 \mathrm{~h}$. Graded amounts of dabrafenib were then added to the cells in $50 \mu \mathrm{l}$ of CM. As a control, melanoma cells were treated with DMSO alone. The plates were incubated at $37^{\circ} \mathrm{C}$ for five days and cell proliferation was then evaluated by the MTT assay, as previously described [57]. Three replica wells were used for each group. Drug concentration producing $50 \%$ inhibition of cell growth (i.e. $\mathrm{IC}_{50}$ ) was calculated on the regression line in which absorbance values at $595 \mathrm{~nm}$ were plotted against the logarithm of drug concentration.

\section{Transient transfection with siRNA and dabrafenib treatment of the transfected cells}

Oligonucleotide siRNA targeting PTTG1 (siPTTG1) and All Star Negative Control (siCTRL) were obtained from Ambion (Austin, TX) and Qiagen (Hilden, Germany), respectively. Transfection was performed using Lipofectamine ${ }^{\mathrm{TM}}$ RNAiMAX reagent (Invitrogen Corporation, Carlsbad, CA) according to the manufacturer's protocol.

For proliferation assays, melanoma cells were suspended in CM without antibiotics, seeded $(100 \mu 1 /$ well $)$ into BD Falcon ${ }^{\mathrm{TM}}$ 96-well plates (BD Biosciences) and allowed to adhere at $37^{\circ} \mathrm{C}$ in a $5 \% \mathrm{CO}_{2}$ atmosphere for $18 \mathrm{~h}$. The cells were then transfected with $10 \mathrm{nM}$ siPTTG1 or siCTRL and analyzed for proliferation three and six days after transfection using the MTT assay. Three replica wells were used for each group.

For chemosensitivity assays, cells were suspended in $\mathrm{CM}$ without antibiotics, seeded into 96-well plates (Falcon), and allowed to adhere at $37^{\circ} \mathrm{C}$ for $18 \mathrm{~h}$. The cells were then transfected with $10 \mathrm{nM}$ siPTTG1 or siCTRL. After $24 \mathrm{~h}$ of incubation, the cells were exposed to DMSO alone or to graded concentrations of dabrafenib (range: 0.048-6.25 nM for A375; 0.195-25 nM for SK-Mel28, $50-6400 \mathrm{nM}$ for A375R and SK-Mel28R). The plates were incubated at $37^{\circ} \mathrm{C}$ for three or five days and cell growth was then evaluated by the MTT assay. Three replica wells were used for each group.

For Western blot analysis, invasion assay and evaluation of MMP-9 secretion, melanoma cells were suspended in $\mathrm{CM}$ without antibiotics, seeded into $\mathrm{BD}$ Falcon $^{\mathrm{TM}} 6 \mathrm{~cm}$-dishes (BD Biosciences), allowed to adhere at $37^{\circ} \mathrm{C}$ for $18 \mathrm{~h}$, and then transfected with $10 \mathrm{nM}$ siPTTG1 or siCTRL. After six days of incubation, the cells were processed for Western blot analysis. Alternatively, $24 \mathrm{~h}$ after transfection, $100 \mathrm{nM}$ dabrafenib or DMSO was added to the cultures and the dishes incubated at $37^{\circ} \mathrm{C}$ for additional $48 \mathrm{~h}$. At the end of the incubation period, culture supernatants were recovered for MMP-9 determination and the cells were detached, counted and processed for Western blot analysis or tested for their ability to invade the ECM in vitro.

\section{Transient transfection with a PTTG1 expression vector and dabrafenib treatment of the transfected cells}

The pCMV6-Entry expression vector encoding a FLAG-tagged PTTG1 protein (CMV-PTTG1) and the empty vector (CMV-EV) were purchased from OriGene Technologies, Inc. (Rockville, MD).

For proliferation assays, melanoma cells were suspended in CM without antibiotics, seeded $(100 \mu 1 /$ well $)$ into BD Falcon ${ }^{\mathrm{TM}}$ 96-well plates (BD Biosciences) and 
allowed to adhere at $37^{\circ} \mathrm{C}$ in a $5 \% \mathrm{CO}_{2}$ atmosphere for 18 h. The cells were then transfected with $5 \mu \mathrm{g}$ CMV-PTTG1 or CMV-EV using Lipofectamine ${ }^{\mathrm{TM}} 2000$ (Invitrogen), according to the manufacturer's protocol. After $24 \mathrm{~h}$ of incubation, medium was replaced with fresh CM without antibiotics and the cells were analyzed for proliferation five days later using the MTT assay. Three replica wells were used for each group.

For chemosensitivity assays, cells were suspended in CM without antibiotics, seeded into 96-well plates (Falcon), and allowed to adhere at $37^{\circ} \mathrm{C}$ for $18 \mathrm{~h}$. The cells were then transfected with $5 \mu \mathrm{g}$ CMV-PTTG1 or CMV-EV. After $24 \mathrm{~h}$ of incubation medium was replaced with fresh CM containing DMSO alone or graded concentrations of dabrafenib (range: $0.048-6.25 \mathrm{nM}$ ). The plates were incubated at $37^{\circ} \mathrm{C}$ for five days and cell growth was then evaluated by the MTT assay. Three replica wells were used for each group.

For Western blot analysis and invasion assay, A375 cells were suspended in CM without antibiotics, seeded into BD Falcon ${ }^{\mathrm{TM}} 6 \mathrm{~cm}$-dishes (BD Biosciences), allowed to adhere at $37^{\circ} \mathrm{C}$ for $18 \mathrm{~h}$, and then transfected with $5 \mu \mathrm{g}$ CMV-PTTG1 or CMV-EV. After $24 \mathrm{~h}$ of incubation, medium was replaced with fresh $\mathrm{CM}$ and the dishes were incubated at $37^{\circ} \mathrm{C}$ for additional five days. A375 cells were then processed for Western blot analysis. Alternatively, $24 \mathrm{~h}$ after transfection medium was replaced with fresh CM containing $100 \mathrm{nM}$ dabrafenib or DMSO and the dishes were incubated at $37^{\circ} \mathrm{C}$ for additional $48 \mathrm{~h}$. Melanoma cells were then processed for Western blot analysis or tested for their ability to invade the ECM in vitro.

\section{Treatment of A375R with LEE011 alone or in combination with dabrafenib}

A375R cells were suspended in CM without antibiotics, seeded into BD Falcon ${ }^{\mathrm{TM}} 6 \mathrm{~cm}$-dishes (BD Biosciences), and allowed to adhere at $37^{\circ} \mathrm{C}$ for $18 \mathrm{~h}$. Thereafter, the cells were exposed to LEE011 (4 $\mu \mathrm{M}$ or $16 \mu \mathrm{M})$, dabrafenib (100 nM) or a combination of LEE011 (4 $\mu \mathrm{M}$ or $16 \mu \mathrm{M})$ plus dabrafenib for $48 \mathrm{~h}$. At the end of the incubation period, the cells were recovered, counted in a hemocytometer to determine cell proliferation, and then assayed for PTTG1 expression and ability to invade the ECM in vitro. Control groups were treated with DMSO alone. A375R were also transfected with $10 \mathrm{nM}$ siPTTG1 or siCTRL and $24 \mathrm{~h}$ later incubated with DMSO or $16 \mu \mathrm{M}$ LEE011. After $48 \mathrm{~h}$ of culture the cells were recovered counted in a hemocytometer to determine cell proliferation and assayed for ECM invasion.

\section{Western blot analysis}

Melanoma cells were recovered from culture, washed and total cellular extracts were prepared as described previously [57]. Fifteen $\mu \mathrm{g}$ of proteins per sample were run on 12\% SDS-polyacrylamide gels, transferred to nitrocellulose membranes (Amersham Biosciences, Buckinghamshire, UK) and blocked with $5 \%$ non-fat milk in Tris-buffered saline supplemented with $0.1 \%$ Tween 20 (TBST-milk) for $1 \mathrm{~h}$ at room temperature. The membranes were then incubated in TBST-milk overnight at $4{ }^{\circ} \mathrm{C}$ with primarys antibodies at the following dilutions: anti- $\beta$-tubulin 1:1000 and anti-PTTG1 1:500. The anti- $\beta$-tubulin antibody was used as an internal standard for loading. Immunodetection was carried out using appropriate horseradish peroxidase-linked secondary antibodies and developed with Clarity ${ }^{\mathrm{TM}}$ Western ECL Substrate (Bio-Rad Laboratories, Inc.). Where indicated, films were scanned on a GS-710 Calibrated Imaging Densitometer and analyzed by means of Quantity One Software Version 4.1.1 (Bio-Rad Laboratories, Inc.).

\section{Invasion assay in Boyden chambers}

This assay was performed as previously described [58]. Briefly, melanoma cells were removed from culture, washed, suspended in invasion medium ( $1 \mu \mathrm{g} / \mathrm{ml}$ heparin/ $0.1 \%$ bovine serum albumin in RPMI$1640)$ and loaded $\left(1 \times 10^{5}\right.$ cells $)$ into the upper compartment of Boyden chambers equipped with $8 \mu \mathrm{m}$ pore diameter polycarbonate filters (Nuclepore, Whatman Inc., Clifton, NJ) coated with $20 \mu \mathrm{g}$ of BD Matrigel ${ }^{\mathrm{TM}}$ Basement $^{\mathrm{T}}$ Membrane Matrix (BD Biosciences). Invasion medium or, where indicated, invasion medium containing $20 \mathrm{ng} / \mathrm{ml}$ VEGF-A (ImmunoTools, Friesoythe, Germany) was added to the lower compartment of the chambers. For each experimental condition, three Boyden chambers were set up. After incubation of the Boyden chambers at $37^{\circ} \mathrm{C}$ in a $5 \% \mathrm{CO}_{2}$ atmosphere for $4 \mathrm{~h}$, the filters were removed from the chambers and the cells were fixed in ethanol for $5 \mathrm{~min}$ and stained in $0.5 \%$ crystal violet for $15 \mathrm{~min}$. The cells from the upper surface of the filter were removed by wiping with a cotton swab and the migrated cells, attached to the lower surface of the filters, were counted under the microscope. Twelve microscopic fields (x200 magnification), randomly selected on triplicate filters, were scored for each experimental condition.

In a set of experiments, invasion assays were performed in the presence of $5 \mu \mathrm{g} / \mathrm{ml}$ of an anti-human MMP-9 mAb (Ab-3, 56-2A4; Calbiochem) or the corresponding control IgG immunoglobulin (MAB002; R\&D Systems, Minneapolis, MN). Melanoma cells were pre-incubated with the $\mathrm{mAb}$ for $30 \mathrm{~min}$ at room temperature in a rotating wheel. The cells were then loaded in the Boyden chambers without removing the mAb.

\section{Evaluation of MMP-9 secretion}

Culture supernatants were collected, centrifuged at $600 \times \mathrm{g}$ for $10 \mathrm{~min}$ to remove cells in suspension and debris, and frozen at $-80^{\circ} \mathrm{C}$ until use. Cells were detached 
with a solution of $1.5 \mathrm{mM}$ EDTA in PBS and counted to determine the total number of cells in the culture. Culture supernatants were concentrated at least ten-fold in Centriplus concentrators (Amicon, Beverly, MA). The amount of active MMP-9 in the culture supernatants was then determined using the Quantikine ELISA Human MMP-9 Immunoassay (R\&D Systems) according to the manufacturer's protocol, and calibrated against a standard curve. The amount MMP-9 was normalized to the number of total cells counted in each culture at the time of supernatant collection.

\section{Patients}

Plasma levels of PTTG1 protein were determined in 22 patients with $\mathrm{BRAF}^{\mathrm{V} 600}$-mutant metastatic cutaneous melanoma consecutively treated with dabrafenib, vemurafenib or dabrafenib plus trametinib at Istituto Dermopatico dell'Immacolata (IDI)-IRCCS and from whom peripheral blood samples had been sequentially collected before therapy commencement and up to disease progression. Baseline evaluation included medical history, physical examination, and radiologic tumor assessment with computer tomography or positron emission tomography scans. Dabrafenib (Tafinlar ${ }^{\circledR}$ ) was given at the dose of $150 \mathrm{mg}$ BID, vemurafenib (Zelboraf ${ }^{\circledR}$ ) at the dose of 960 mg BID and dabrafenib plus trametinib (Mekinist ${ }^{\circledR}$ ) at the dose of $150 \mathrm{mg}$ BID and $2 \mathrm{mg}$ /die, respectively. All patients underwent physical examination and assessment of biochemical parameters monthly, whereas tumor response was determined with CT every three months. Tumor response was classified as complete response, partial response, stable disease or progressive disease according to RECIST 1.1 criteria [59]. Time to treatment failure was defined as the time from the start of therapy to the first observation of disease progression per RECIST 1.1. The study was conducted in accordance with Good Clinical Practice Guidelines and the Declaration of Helsinki. The study was also approved by the IDI-IRCCS Ethics Committee (ID \#407/1, 2013 and \#407/2, 2016) and a written informed consent was obtained from all patients.

\section{Plasma preparation and PTTG1 evaluation}

Blood was collected into BD Vacutainer ${ }^{\circledR}$ tubes (\#367704, BD Biosciences, Plymouth, UK), double centrifuged at $1,200 \times \mathrm{g}$ for 10 minutes at $4 \mathrm{C}^{\circ}$, and the plasma stored at $-80^{\circ} \mathrm{C}$ within $2 \mathrm{~h}$ from collection.

PTTG1 amount in plasma samples was determined using Human Securin (PTTG1) ELISA Kit (MyBioSource, Inc., San Diego, CA) according to the manufacturer's instructions. All determinations were performed in duplicate. A value of $0.1 \mathrm{ng} / \mathrm{mL}$ was the lower limit of PTTG1 detection of the ELISA kit. Therefore, for data analysis, assay values under the lower limit of ELISA detection were replaced with $0.01 \mathrm{ng} / \mathrm{mL}$ as previously described [60].

\section{Statistical analysis}

Statistical significance of the differences among experimental groups was assessed using unpaired twoside Student's $t$-test, whereas statistical significance of the differences between PTTG1 plasma levels at different time points (T2 versus $\mathrm{T} 0$ and $\mathrm{TP}$ versus $\mathrm{T} 2$ ) in each melanoma patient was assessed using paired two-side Student's $t$-test. Significance was set at $P<0.05$.

Plasma levels of PTTG1 were also reported as medians and Interquartile Range (IQR) and were analysed using nonparametric procedures. The Mann-Whitney $U$-test was used to compare between-group differences, while the Wilcoxon matched-pairs signed-rank test was used to evaluate before-after differences. Nonparametric analyses were conducted using STATA11 (Stata Corp. LP, College Station, TX).

\section{Abbreviations}

BRAFi: BRAF inhibitor; CM: complete medium; DMSO: dimethyl sulfoxide; ECM: extracellular matrix; IC: inhibitory concentration; MAPK: mitogen-activated protein kinase; MEKi: MEK inhibitor; MMP: matrix metalloproteinase; MTT: 3-(4,5-dimethylthiazol-2-yl)2,5-diphenyltetrazolium bromide; PTTG1: pituitary tumor transforming gene 1; siRNA: small interfering RNA; PBS: phosphate buffered saline; SDS: sodium dodecyl sulphate; SEM: standard error of the mean; TBST: Tris-buffered saline/Tween 20; VEGF: vascular endothelial growth factor; vs, versus.

\section{Author contributions}

Study conception and design: SC, SD. Data acquisition: SC, EA, PML, FR, LL, LB. Data Analysis and interpretation: SC, EA, PML, FR, LL, SM, GCA, SD. Patient treatment and follow-up: GCA, AS, PM. Writing of the manuscript: SC, SD.

\section{ACKNOWLEDGMENTS}

The authors thank GlaxoSmithKline for the supply of dabrafenib, and Maurizio Inzillo (Office of External Relations and Communication, IDI-IRCCS) for the artwork.

\section{CONFLICTS OF INTEREST}

The authors declare non conflict of interest.

\section{FUNDING}

This work was supported by the Italian Association for Cancer Research (AIRC, Investigator Grant Project 
17585) and by the Italian Ministry of Health (Grant 5PerMille-2010).

\section{REFERENCES}

1. Vlotides G, Eigler T, Melmed S. Pituitary tumortransforming gene: Physiology and implications for tumorigenesis. Endocr Rev. 2007; 28:165-86.

2. Panguluri SK, Yeakel C, Kakar SS. PTTG: An important target gene for ovarian cancer therapy. J Ovarian Res. 2008; $1: 6$.

3. Tong Y, Eigler T. Transcriptional targets for pituitary tumortransforming gene-1. J Mol Endocrinol. 2009; 43:179-85.

4. Smith VE, Franklyn JA, McCabe CJ. Pituitary tumortransforming gene and its binding factor in endocrine cancer. Expert Rev Mol Med. 2010; 12:e38.

5. Pei L, Melmed S. Isolation and Characterization of a Pituitary Tumor-Transforming Gene (PTTG). Mol Endocrinol. 1997; 11:433-41.

6. Kakar SS, Jennes L. Molecular cloning and characterization of the tumor transforming gene (TUTR1): a novel gene in human tumorigenesis. Cytogenet Cell Genet. 1999; 84:211-6.

7. Yoon CH, Kim MJ, Lee H, Kim RK, Lim EJ, Yoo KC, Lee GH, Cui YH, Oh YS, Gye MC, Lee YY, Park IC, An S, et al. PTTG1 oncogene promotes tumor malignancy via epithelial to mesenchymal transition and expansion of cancer stem cell population. J Biol Chem. 2012; 287:19516-27.

8. Li H, Yin C, Zhang B, Sun Y, Shi L, Liu N, Liang S, Lu S, Liu Y, Zhang J, Li F, Li W, Liu F, et al. PTTG1 promotes migration and invasion of human non-small cell lung cancer cells and is modulated by miR-186. Carcinogenesis. 2013; $34: 2145-55$.

9. Wang Y, Zang W, Du Y, Ma Y, Li M, Li P, Chen X, Wang T, Dong Z, Zhao G. Mir-655 up-regulation suppresses cell invasion by targeting pituitary tumor-transforming gene-1 in esophageal squamous cell carcinoma. J Transl Med. $2013 ; 11: 301$.

10. Zhou C, Tong Y, Wawrowsky K, Melmed S. PTTG acts as a STAT3 target gene for colorectal cancer cell growth and motility. Oncogene. 2014; 33:851-61.

11. Li L, Han LY, Yu M, Zhou Q, Xu JC, Li P. Pituitary tumortransforming gene 1 enhances metastases of cervical cancer cells through miR-3666-regulated ZEB1. Tumour Biol. 2016; 37:15567-73.

12. Xiang $\mathrm{W}, \mathrm{Wu} \mathrm{X}$, Huang $\mathrm{C}$, Wang M, Zhao X, Luo G, Li Y, Jiang G, Xiao X, Zeng F. PTTG1 regulated by miR-146-3p promotes bladder cancer migration, invasion, metastasis and growth. Oncotarget. 2017; 8:664-78. http://doi.org/10.18632/ oncotarget.13507.

13. Winnepenninckx V, Debiec-Rychter M, Beliën JAM, Fiten P, Michiels S, Lazar V, Opdenakker G, Meijer GA, Spatz A, van den Oord JJ. Expression and possible role of hPTTG1/ securin in cutaneous malignant melanoma. Mod Pathol. 2006; 19:1170-80.
14. Ramaswamy S, Ross KN, Lander ES, Golub TR. A molecular signature of metastasis in primary solid tumors. Nat Genet. 2002; 33:49-54.

15. Kauffmann A, Rosselli F, Lazar V, Winnepenninckx V, Mansuet-Lupo A, Dessen P, van den Oord JJ, Spatz A, Sarasin A. High expression of DNA repair pathways is associated with metastasis in melanoma patients. Oncogene. $2008 ; 27: 565-73$.

16. Winnepenninckx V, Lazar V, Michiels S, Dessen P, Stas M, Alonso SR, Avril MF, Ortiz Romero PL, Robert T, Balacescu O, Eggermont AMM, Lenoir G, Sarasin A, et al. Gene Expression Profiling of Primary Cutaneous Melanoma and Clinical Outcome. J Natl Cancer Inst. 2006; 98:472-82.

17. Zhang G, Zhao Q, Yu S, Lin R, Yi X. Pttg1 inhibits TGF $\beta$ signaling in breast cancer cells to promote their growth. Tumor Biol. 2014; 36:199-203.

18. Lin YH, Tian Y, Wang JS, Jiang YG, Luo Y, Chen YT. Pituitary tumor-transforming gene 1 regulates invasion of prostate cancer cells through MMP13. Tumour Biol. 2016; 37:15495-500.

19. Chen B, Hou Z, Li C, Tong Y. MiRNA-494 inhibits metastasis of cervical cancer through Pttg1. Tumor Biol. 2015; 36:7143-9.

20. Zhang E, Liu S, Xu Z, Huang S, Tan X, Sun C, Lu L. Pituitary tumor-transforming gene 1 (PTTG1) is overexpressed in oral squamous cell carcinoma (OSCC) and promotes migration, invasion and epithelial-mesenchymal transition (EMT) in SCC15 cells. Tumor Biol. 2014; 35:8801-11.

21. Yan H, Wang W, Dou C, Tian F, Qi S. Securin promotes migration and invasion via matrix metalloproteinases in glioma cells. Oncol Lett. 2015; 9:2895-901.

22. Li WH, Chang L, Xia YX, Wang L, Liu YY, Wang YH, Jiang Z, Xiao J, Wang ZR. Knockdown of PTTG1 inhibits the growth and invasion of lung adenocarcinoma cells through regulation of TGFB1/SMAD3 signaling. Int $\mathrm{J}$ Immunopathol Pharmacol. 2015; 28:45-52.

23. Bernal JA, Luna R, Espina Á, Lázaro I, Ramos-Morales F, Romero F, Arias C, Silva A, Tortolero M, Pintor-Toro JA. Human securin interacts with p53 and modulates p53mediated transcriptional activity and apoptosis. Nat Genet. 2002; 32:306-11.

24. Kho PS, Wang Z, Zhuang L, Li Y, Chew JL, Ng HH, Liu ET, Yu Q. p53-regulated transcriptional program associated with genotoxic stress-induced apoptosis. J Biol Chem. 2004; 279:21183-92.

25. Bernal JA, Roche M, Méndez-Vidal C, Espina A, Tortolero M, Pintor-Toro JA. Proliferative potential after DNA damage and non-homologous end joining are affected by loss of securin. Cell Death Differ. 2008; 15:202-12.

26. Tong Y, Zhao W, Zhou C, Wawrowsky K, Melmed S. PTTG1 attenuates drug-induced cellular senescence. PLoS One. 2011; 6:e23754.

27. Ghayad SE, Vendrell JA, Bleche I, Spyratos F, Dumontet C, Treilleux I, Lidereau R, Cohen PA. Identification of TACC1, 
NOV, and PTTG1 as new candidate genes associated with endocrine therapy resistance in breast cancer. J Mol Endocrinol. 2009; 42:87-103.

28. Yu SY, Liu HF, Wang SP, Chang CC, Tsai CM, Chao JI. Evidence of securin-mediated resistance to gefitinibinduced apoptosis in human cancer cells. Chem Biol Interact. 2013; 203:412-22.

29. Nakachi I, Helfrich BA, Spillman MA, Mickler EA, Olson CJ, Rice JL, Coldren CD, Heasley LE, Geraci MW, Stearman RS. PTTG1 Levels Are Predictive of Saracatinib Sensitivity in Ovarian Cancer Cell Lines. Clin Transl Sci. 2016; 9:293-301.

30. Caporali S, Alvino E, Levati L, Esposito AI, Ciomei M, Brasca MG, Del Bufalo D, Desideri M, Bonmassar E, Pfeffer U, D'Atri S. Down-regulation of the PTTG1 protooncogene contributes to the melanoma suppressive effects of the cyclin-dependent kinase inhibitor PHA-848125. Biochem Pharmacol. 2012; 84:598-611.

31. Caporali S, Alvino E, Lacal PM, Levati L, Giurato G, Memoli D, Caprini E, Antonini Cappellini GC, D’Atri S. Targeting the PI3K/AKT/mTOR pathway overcomes the stimulating effect of dabrafenib on the invasive behavior of melanoma cells with acquired resistance to the BRAF inhibitor. Int J Oncol. 2016; 49:1164-74.

32. Weiss GJ, Hidalgo M, Borad MJ, Laheru D, Tibes R, Ramanathan RK, Blaydorn L, Jameson G, Jimeno A, Isaacs JD, Scaburri A, Pacciarini MA, Fiorentini F, et al. Phase I study of the safety, tolerability and pharmacokinetics of PHA-848125AC, a dual tropomyosin receptor kinase A and cyclin-dependent kinase inhibitor, in patients with advanced solid malignancies. Invest New Drugs. 2012; 30:2334-43.

33. Xia YH, Li M, Fu DD, Xu SL, Li ZG, Liu D, Tian ZW. Effects of PTTG down-regulation on proliferation and metastasis of the SCL-1 cutaneous squamous cell carcinoma cell line. Asian Pac J Cancer Prev. 2013; 14:6245-8.

34. Lim SM, Jang HY, Lee JE, Shin JS, Park S. Alteration of Pituitary Tumor Transforming Gene-1 Regulates Trophoblast Invasion via the Integrin/Rho-Family Signaling Pathway. 2016; 11:e0149371.

35. Orgaz JL, Sanz-Moreno V. Emerging molecular targets in melanoma invasion and metastasis. Pigment Cell Melanoma Res. 2013; 26:39-57.

36. Simonetti O, Lucarini G, Brancorsini D, Nita P, Bernardini ML, Biagini G, Offidani A. Immunohistochemical expression of vascular endothelial growth factor, matrix metalloproteinase 2, and matrix metalloproteinase 9 in cutaneous melanocytic lesions. Cancer. 2002; 95:1963-70.

37. Wang M, Xia X, Chu W, Xia L, Meng T, Liu L, Liu Y. Roles of miR-186 and PTTG1 in colorectal neuroendocrine tumors. Int J Clin Exp Med. 2015; 8:22149-57.

38. Balch CM, Gershenwald JE, Soong SJ, Thompson JF, Atkins MB, Byrd DR, Buzaid AC, Cochran AJ, Coit DG, Ding S, Eggermont AM, Flaherty KT, Gimotty PA, et al. Final version of 2009 AJCC melanoma staging and classification. J Clin Oncol. 2009; 27:6199-206.
39. Queirolo P, Picasso V, Spagnolo F. Combined BRAF and MEK inhibition for the treatment of BRAF-mutated metastatic melanoma. Cancer Treat Rev. 2015; 41:519-26.

40. Eroglu Z, Ribas A. Combination therapy with BRAF and MEK inhibitors for melanoma: latest evidence and place in therapy. Ther Adv Med Oncol. 2015; 8:48-56.

41. Liu M, Yang X, Liu J, Zhao B, Cai W, Li Y, Hu D. Efficacy and safety of BRAF inhibition alone versus combined BRAF and MEK inhibition in melanoma: a meta- analysis of randomized controlled trials. Oncotarget. 2017; 8:3225869. http://doi.org/10.18632/oncotarget.15632.

42. Sullivan RJ, Flaherty KT. Resistance to BRAF-targeted therapy in melanoma. Eur J Cancer. 2013; 49:1297-304.

43. Spagnolo F, Ghiorzo P, Queirolo P. Overcoming resistance to BRAF inhibition in BRAF-mutated metastatic melanoma. Oncotarget. 2014; 5:10206-21. http://doi.org/10.18632/ oncotarget.2602.

44. Van Allen EM, Wagle N, Sucker A, Treacy DJ, Johannessen CM, Goetz EM, Place CS, Taylor-Weiner A, Whittaker S, Kryukov GV, Hodis E, Rosenberg M, McKenna A, et al. The genetic landscape of clinical resistance to RAF inhibition in metastatic melanoma. Cancer Discov. 2014; 4:94-109.

45. Zhuu Y, Mehta KR, Choi AP, Solavino S, Zhang X. DNA damage-induced inhibition of securin expression is mediated by p53. J Biol Chem. 2003; 278:462-70.

46. Ikediobi ON, Davies H, Bignell G, Edkins S, Stevens C, O'Meara S, Santarius T, Avis T, Barthorpe S, Brackenbury L, Buck G, Butler A, Clements J, et al. Mutation analysis of 24 known cancer genes in the NCI-60 cell line set. Mol Cancer Ther. 2006; 5: 2606-12.

47. Yamanaka S, Campbell NR, An F, Kuo SC, Potter JJ, Mezey E, Maitra A, Selaru FM. Coordinated effects of microRNA-494 induces G2/M arrest in human cholangiocarcinoma. Cell Cycle. 2012; 11:2729-38.

48. Liang H, Wang R, Diao C, Li J, Su J, Zhang S. The PTTG1targeting miRNAs miR-329, miR-300, miR-381, and miR-655 inhibit pituitary tumor cell tumorigenesis and are involved in a p53/PTTG1 regulation feedback loop. Oncotarget. 2015; 6:29413-27. http://doi.org/10.18632/ oncotarget.5003.

49. Hernández A, López-Lluch G, Bernal JA, Navas P, PintorToro J. Dicoumarol down-regulates human PTTG1/Securin mRNA expression through inhibition of Hsp90. Mol Cancer Ther. 2008; 7:474-82.

50. Chan MMK, Haydu LE, Menzies AM, Azer MWF, Klein O, Lyle M, Clements A, Guminski A, Kefford RF, Long GV. The nature and management of metastatic melanoma after progression on BRAF inhibitors: Effects of extended BRAF inhibition. Cancer. 2014; 120:3142-53.

51. Scholtens A, Geukes Foppen MH, Blank CU, van Thienen JV, van Tinteren H, Haanen JB. Vemurafenib for BRAF V600 mutated advanced melanoma: Results of treatment beyond progression. Eur J Cancer. 2015; 51:642-52. 
52. Infante JR, Cassier PA, Gerecitano JF, Witteveen PO, Chugh R, Ribrag V, Chakraborty A, Matano A, Dobson JR, Crystal AS, Parasuraman S, Shapiro GI. A Phase I Study of the Cyclin-Dependent Kinase 4/6 Inhibitor Ribociclib (LEE011) in Patients with Advanced Solid Tumors and Lymphomas. Clin Cancer Res. 2016; 22:5696-705.

53. Miller DM, Flaherty KT. Cyclin-dependent kinases as therapeutic targets in melanoma. Pigment Cell Melanoma Res. 2014; 27:351-65.

54. Hamilton E, Infante JR. Targeting CDK4/6 in patients with cancer. Cancer Treat Rev. 2016; 45:129-38.

55. O'Leary B, Finn RS, Turner NC. Treating cancer with selective CDK4/6 inhibitors. Nat Rev Clin Oncol. 2016; 13:417-30.

56. Yadav V, Burke TF, Huber L, Van Horn RD, Zhang Y, Buchanan SG, Chan EM, Starling JJ, Beckmann RP, Peng SB. The CDK4/6 inhibitor LY2835219 overcomes vemurafenib resistance resulting from MAPK reactivation and cyclin D1 upregulation. Mol Cancer Ther. 2014; 13:2253-63.
57. Caporali S, Falcinelli S, Starace G, Russo MT, Bonmassar E, Jiricny J, D'Atri S. DNA damage induced by temozolomide signals to both ATM and ATR: role of the mismatch repair system. Mol Pharmacol. 2004; 66:478-91.

58. Ruffini F, D'Atri S, Lacal PM. Neuropilin-1 expression promotes invasiveness of melanoma cells through vascular endothelial growth factor receptor-2-dependent and -independent mechanisms. Int J Oncol. 2013; 43:297-306.

59. Eisenhauer EA, Therasse P, Bogaerts J, Schwartz LH, Sargent D, Ford R, Dancey J, Arbuck S, Gwyther S, Mooney M, Rubinstein L, Shankar L, Dodd L, et al. New response evaluation criteria in solid tumours: Revised RECIST guideline (version 1.1). Eur J Cancer. 2009; 45:228-47.

60. Zhou J, Mahoney KM, Giobbie-Hurder A, Zhao F, Lee S, Liao X, Rodig S, Li J, Wu X, Butterfield LH, Piesche M, Manos MP, Eastman LM, et al. Soluble PD-L1 as a Biomarker in Malignant Melanoma Treated with Checkpoint Blockade. Cancer Immunol Res. 2017; 5:480-92. 